\title{
Glutathione-degradable drug-loaded nanogel effectively and securely suppresses hepatoma in mouse model
}

This article was published in the following Dove Press journal:

International Journal of Nanomedicine

22 October 2015

Number of times this article has been viewed

\author{
Xingang Liu' \\ Jianmeng Wang ${ }^{2}$ \\ Weiguo $\mathrm{Xu}^{3}$ \\ Jianxun Ding ${ }^{3}$ \\ Bo $\mathrm{Shi}^{4}$ \\ Kexin Huang ${ }^{4}$ \\ Xiuli Zhuang ${ }^{3}$ \\ Xuesi Chen ${ }^{3}$ \\ 'Department of Critical Care \\ Medicine, ${ }^{2}$ Department of Geriatrics, \\ The First Hospital of Jilin University, \\ ${ }^{3}$ Key Laboratory of Polymer \\ Ecomaterials, Changchun Institute of \\ Applied Chemistry, Chinese Academy \\ of Sciences, ${ }^{4}$ Center for Biological \\ Experiment, College of Basic \\ Medicine, Jilin University, Changchun, \\ People's Republic of China
}

\begin{abstract}
The reduction-responsive polymeric nanocarriers have attracted considerable interest because of a significantly higher concentration of intracellular glutathione in comparison with that outside cells. The smart nanovehicles can selectively transport the antitumor drugs into cells to improve efficacies and decrease side effects. In this work, a facilely prepared glutathionedegradable nanogel was employed for targeting intracellular delivery of an antitumor drug (ie, doxorubicin [DOX]). DOX was loaded into nanogel through a sequential dispersion and dialysis approach with a drug loading efficiency of $56.8 \mathrm{wt} \%$, and the laden nanogel (noted as NG/DOX) showed an appropriate hydrodynamic radius of $56.1 \pm 3.5 \mathrm{~nm}$. NG/DOX exhibited enhanced or improved maximum tolerated dose on healthy Kunming mice and enhanced intratumoral accumulation and dose-dependent antitumor efficacy toward $\mathrm{H} 22$ hepatoma-xenografted mouse model compared with free drug. In addition, the upregulated antitumor efficacy of $\mathrm{NG} / \mathrm{DOX}$ was further confirmed by the histopathological and immunohistochemical analyses. Furthermore, the excellent in vivo security of NG/DOX was confirmed by the detection of body weight, histopathology, and biochemical indices of corresponding organs and serum. With controllable large-scale preparation and fascinating in vitro and in vivo properties, the reduction-responsive nanogel exhibited a good prospect for clinical chemotherapy.
\end{abstract}

Keywords: antitumor efficacy, chemotherapy, controlled release, nanogel, reductionresponsiveness, security

\section{Introduction}

At present, the specific microenvironment in tumor cells has attracted broad interests of researchers in the field of pharmaceutics. ${ }^{1-3}$ As the focus of attention, the intracellular components of tumor cells exhibit a more reductive condition in comparison with that outside cells. ${ }^{4,5}$ In detail, the glutathione (GSH) concentration in cells $(0.5-10.0 \mathrm{mM})$ is about three orders of magnitude higher than that outside cells $(2.0-20.0 \mu \mathrm{M}){ }^{6-9}$ The potential difference of GSH concentration between extracellular region and intracellular organelles provides the possibility to design the reduction-responsive polymeric nanocarriers for selective intracellular drug delivery. ${ }^{10}$

Right now, most of the reduction-responsive polymeric nanovehicles contain the component of disulfide bond, which can degrade into two mercapto groups triggered by the high concentration of intracellular GSH along with the expansion or even disintegration of nanoparticles and the release of payloads. ${ }^{11,12}$ Among all the smart nanoparticles, the reduction-responsive polymeric nanogels account for a large proportion ascribed to the superior performances: 1) tunable and stable chemical and physical structures, 2) excellent drug loading capacity, 3) selective accumulation in tumor tissue via the enhanced 
permeability and retention (EPR) effect, and 4) quick drug release in the intracellular reduction condition. ${ }^{13,14}$

In 2006, Li et al reported the synthesis of reversible shell crosslinked micelle by the amidation reaction of an $N$-acryloxysuccinimide in poly(ethylene oxide)-block-((N,Ndimethylacrylamide)-co-( $N$-acryloxysuccinimide $))$-block-( $N$ isopropylacrylamide) (PEO- $b$-P(DMA-co-NAS)- $b$-NIPAM) with cystamine, which acted as a disulfide bifunctional primary amine crosslinker. ${ }^{15}$ The resultant amide linkage between cystamine and polymer was stable, while the disulfide bond in cystamine could be cleaved by reducing agents (eg, dithiothreitol and tris(2-carboxyethyl)-phosphine) that are ready to impart reversible crosslinking characteristic to the nanoparticle. The reversible crosslinkable micelle exhibited greater potential in the field of drug delivery due to the selective cleavage of disulfide bond, which could occur under the reducing condition within the target lesion cells and enable a controlled intracellular drug release. Subsequently, a variety of disulfide bond-crosslinked nanogels have been prepared for selective intracellular drug delivery. As a typical example, Koo et al synthesized the disulfide shell crosslinked PEG-poly(amino acid)s micelle with the same amidation reaction for the delivery of methotrexate (MTX), which was a model hydrophobic drug for the therapeutics of osteosarcoma, lung, and breast cancers in clinic. ${ }^{16}$ The loading nanogel released MTX in response to an intracellular GSH level and showed enhanced cytotoxicity toward the human lung carcinoma A549 cells pretreated with $10.0 \mathrm{mM}$ GSH. In addition, Wei et al developed a reduction-responsive reversible core crosslinked micelle based on poly(ethylene glycol)-block-poly(( $N$-2-hydroxypropyl methacrylamide)-co- $N$-2-hydroxypropyl methacrylamidegraft-lipoic acid) (PEG-b-P(HPMA-co-(HPMA-g-LA))), which was investigated for triggered doxorubicin (DOX) release. ${ }^{17}$ As expected, the laden disulfide-crosslinked system exhibited improved intracellular DOX release and enhanced cellular proliferation inhibition in vitro.

During the same period, that is, in the past decade, many other reduction-responsive nanogels have been investigated through thiol-disulfide exchange reaction, ${ }^{18} \mathrm{Cu}(\mathrm{I})$-catalyzed "click chemistry" reaction, ${ }^{19}$ quaternization reaction, ${ }^{5}$ onestep ring-opening polymerization (ROP), ${ }^{6,20,21}$ and so on. In this work, a reduction-responsive methoxy poly(ethylene glycol)-poly(L-phenylalanine-co-L-cystine) (mPEG-P(LPco-LC)) nanogel with facile preparation process and controllable performances was synthesized by our previously reported one-step ROP of L-phenylalanine $N$-carboxyanhydride (LP NCA) and L-cystine $N$-carboxyanhydride (LC NCA) with amino-terminated $\mathrm{mPEG}$ as a macroinitiator for targeting intracellular drug delivery in vivo (Figure 1). ${ }^{6}$ DOX was employed as a model antitumor drug. Besides the excellent biocompatibility and selective accumulation in tumor tissue, the DOX-loaded nanogel (NG/DOX) exhibited effective and safe tumor inhibition toward H22 hepatoma-xenografted $\mathrm{BALB} / \mathrm{c}$ mouse model, indicating good prospect for the clinical chemotherapy of malignancy.

\section{Materials and methods Materials}

As shown in Figure 1, the reduction-responsive $\mathrm{mPEG}_{113}-\mathrm{P}_{\left(\mathrm{LP}_{12}\right.}{ }^{-}$ co- $\mathrm{LC}_{2}$ ) nanogel was synthesized through the one-step ROP according to our previous works. ${ }^{4,6}$ The subscript number represented the degree of polymerization of each component, which was calculated from elemental analysis. As shown in Figure 2, the morphology and hydrodynamic radius $\left(R_{\mathrm{h}}\right)$ of nanogel were detected to be spherical and $56.1 \pm 3.8 \mathrm{~nm}$ by transmission electron microscopy and dynamic light scattering (DLS), respectively. Doxorubicin hydrochloride $(\mathrm{DOX} \cdot \mathrm{HCl})$ was purchased from Beijing Huafeng United Technology Co., Ltd. (Beijing, People's Republic of China). NG/DOX was prepared by a sequential dispersion and dialysis approach. Hematoxylin and eosin (H\&E) were obtained from EMD Millipore (Billerica, MA, USA). The commercial enzymelinked immunosorbent assay (ELISA) kits of creatine kinase isoenzyme (CK-MB), lactate dehydrogenase ( $\mathrm{LDH})$, alanine aminotransferase (ALT), aspartate aminotransferase (AST), blood urea nitrogen (BUN), and creatinine $(\mathrm{Cr})$ were purchased from Nanjing Jiancheng Bioengineering Co., Ltd. (Nanjing, People's Republic of China). Caspase-3, survivin, Bax, and Bcl-2 antibodies were purchased from Abcam Company (Cambridge, UK). SP9710 and DAB chromogenic kits were purchased from Fuzhou Maixin Biotechnology Development Company (Fuzhou, People's Republic of China).

\section{Animal procedures}

Equal number of the male and female Kunming mice (5 weeks old, $\sim 22 \mathrm{~g}$ ) were obtained from the Laboratory Animal Center of Jilin University for the detection of maximum tolerated dose (MTD). In addition, 5-week-old male $\mathrm{BALB} / \mathrm{c}$ mice weighting $19.5 \pm 1.5 \mathrm{~g}$ were provided by Beijing HFK Bioscience Co., Ltd. (Beijing, People's Republic of China) for both tissue distribution and antitumor assays. All animal experiments were approved by the Animal Care and Use Committee of Jilin University and were conducted in accordance with its Guidelines, and all efforts were made to minimize the suffering. To induce tumor, the mice were given subcutaneous injection in the armpits of right anterior limbs with $0.1 \mathrm{~mL}$ of cell suspension containing $2.0 \times 10^{6}$ mouse hepatoma $\mathrm{H} 22$ cells in phosphate buffered saline (PBS). 


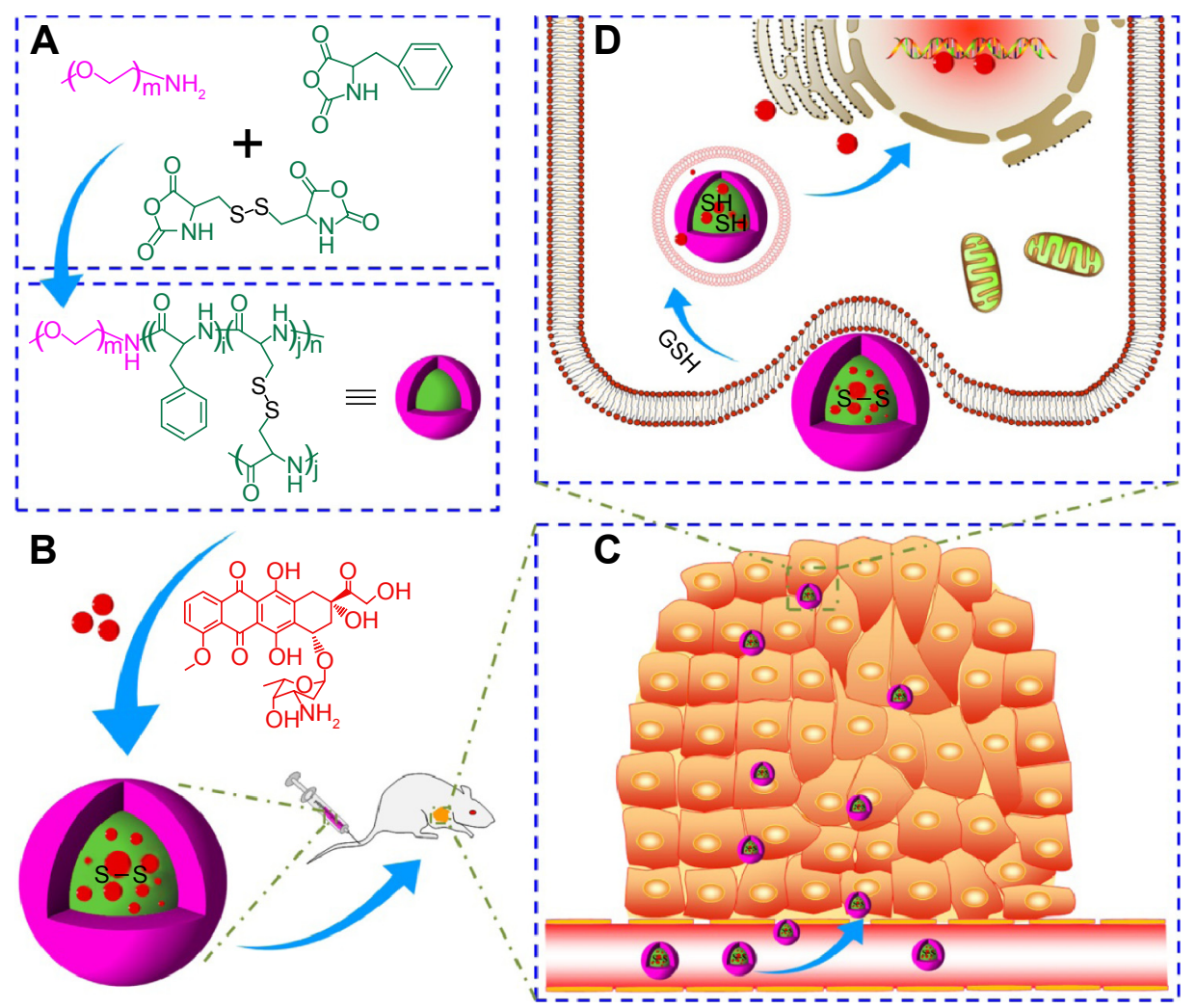

Figure I Synthetic pathway for mPEG-P(LP-co-LC) nanogel and schematic illustrations about circulation, intratumoral accumulation, endocytosis, and targeting intracellular DOX release of DOX-loaded nanogel after intravenous injection.

Notes: $\mathrm{mPEG}-\mathrm{P}(\mathrm{LP}-\mathrm{co}-\mathrm{LC})$ nanogel synthesis (A), DOX encapsulation and intravenous injection (B), in vivo circulation and intratumoral accumulation (C), and endocytosis and GSH-triggered intracellular DOX release (D). All the arrows indicate the preparation and in vivo metabolic process of DOX-loaded nanogel. Abbreviations: DOX, doxorubicin; GSH, glutathione; mPEG-P(LP-co-LC), methoxy poly(ethylene glycol)-poly(L-phenylalanine-co-L-cystine).

\section{Evaluation of MTD}

Equal number of male $(\mathrm{n}=90)$ and female Kunming mice $(\mathrm{n}=90)$ were used to evaluate the MTDs of nanogel, free DOX $\cdot \mathrm{HCl}$, and NG/DOX. All of the groups received a singledose by intravenous (IV) injection ( $\mathrm{n}=20$ for each group). The mice in the free DOX $\cdot \mathrm{HCl}$ and $\mathrm{NG} / \mathrm{DOX}$ groups received

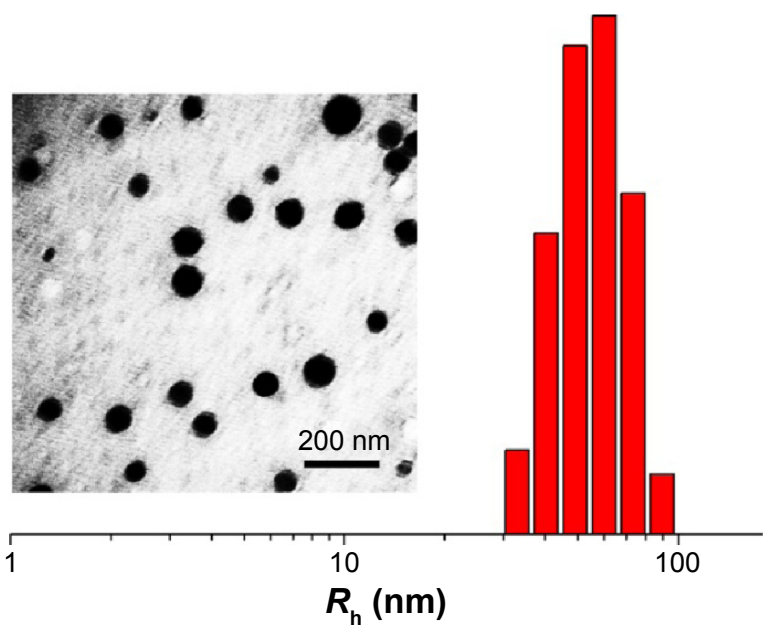

Figure 2 Typical TEM microimage and $R_{\mathrm{h}}$ of mPEG-P(LP-co-LC) nanogel. Abbreviations: TEM, transmission electron microscopy; $R_{h}$, hydrodynamic radius; mPEG-P(LP-co-LC), methoxy poly(ethylene glycol)-poly(L-phenylalanine-co-L-cystine). a DOX $\cdot \mathrm{HCl}$ dose of $5.0 \mathrm{mg}$ per $\mathrm{kg}$ body weight $(\mathrm{mg}[\mathrm{kg}$ $\left.\mathrm{BW}]^{-1}\right), 10.0 \mathrm{mg}(\mathrm{kg} \mathrm{BW})^{-1}$, or $15.0 \mathrm{mg}(\mathrm{kg} \mathrm{BW})^{-1}$. The control group received $100.0 \mathrm{mg}(\mathrm{kg} \mathrm{BW})^{-1}, 300.0 \mathrm{mg}(\mathrm{kg} \mathrm{BW})^{-1}$, or $500.0 \mathrm{mg}(\mathrm{kg} \mathrm{BW})^{-1}$ of nanogel. MTD was defined as the allowance of a $15 \%$ median loss of body weight before pharmacological treatment without death due to toxic effects or remarkable changes in the general signs within 10 days after administration. ${ }^{22,23}$ In addition, the mice were sacrificed on Day 11. The major organs, that is, heart, liver, spleen, lung, and kidney, were isolated, washed with PBS, and weighted precisely. The organ indices of all the aforementioned organs of mice were calculated using Equation 1.

$$
\text { Organ index }(\%)=\frac{W_{\text {organ }}(\mathrm{mg})}{W_{\text {body }}(\mathrm{g})},
$$

where $W_{\text {organ }}(\mathrm{mg})$ and $W_{\text {body }}(\mathrm{g})$ were denoted as the weights of organ and body, respectively.

\section{Ex vivo DOX fluorescence imaging}

The tissue distribution of DOX after IV injection of different formulations with various doses were qualitatively or semiquantitatively assessed by ex vivo DOX fluorescence imaging 
of tumor and major internal organs. When the tumor grew up to approximately $250 \mathrm{~mm}^{3}$, free $\mathrm{DOX} \cdot \mathrm{HCl}$ or $\mathrm{NG} / \mathrm{DOX}$ at a DOX $\cdot \mathrm{HCl}$ dose of $3.0 \mathrm{mg}(\mathrm{kg} \mathrm{BW})^{-1}$ or $6.0 \mathrm{mg}(\mathrm{kg} \mathrm{BW})^{-1}$ was intravenously injected. The tumor-bearing BALB/c mice were sacrificed at 12 hours postinjection, and the tumor and major organs, including kidney, heart, spleen, lung, and liver, were excised and washed with PBS. The ex vivo DOX fluorescence imaging was obtained using the Maestro 500FL in vivo Imaging System (Cambridge Research and Instrumentation Inc., Woburn, MA, USA). In addition, the average signals were also semi-quantitatively analyzed using a Maestro $^{\text {TM }} 2.4$ software from the same company.

\section{In vivo antitumor assessments}

From the second day after the inoculation of H22 cells, that is, Day 1, the tumor volumes and body weights were monitored every 2 days. Seven days after inoculation, the tumor volume grew to approximately $400 \mathrm{~mm}^{3}$, and then the mice were randomly divided into five groups $(n=10)$, that is, normal saline (NS), free $\mathrm{DOX} \cdot \mathrm{HCl}$, or $\mathrm{NG} / \mathrm{DOX}$ at a $\mathrm{DOX} \cdot \mathrm{HCl}$ dosage of $3.0 \mathrm{mg}(\mathrm{kg} \mathrm{BW})^{-1}$ or $6.0 \mathrm{mg}(\mathrm{kg} \mathrm{BW})^{-1}$. The DOX formulations were noted as DOX/3.0, DOX/6.0, $\mathrm{NG} / \mathrm{DOX} / 3.0$, and $\mathrm{NG} / \mathrm{DOX} / 6.0$. At the same time, the treatments were started, that is, $100.0 \mu \mathrm{L}$ of NS and various DOX formulations in NS were injected into tail vein for four times every 5 days. The antitumor efficacy and security in vivo were evaluated by detecting the tumor volumes and body weights. The tumor volumes were calculated according to Equation 2.

$$
V\left(\mathrm{~mm}^{3}\right)=\frac{L \times S^{2}}{2} .
$$

In Equation 2, $L$ and $S(\mathrm{~mm})$ were the largest and smallest diameters of tumor, respectively, which were measured by a vernier caliper.

\section{Histopathological and immunohistochemical analyses of tumor tissues}

The H22 hepatoma-xenografted mice were sacrificed by cervical dislocation on Day 25, that is, 3 days after the last injection. The tumors were isolated and fixed in $4 \%(\mathrm{~W} / \mathrm{V})$ paraformaldehyde for 24 hours, followed by dehydration, clearing, wax infiltration, and embedding. A total of $5 \mu \mathrm{m}$ thick paraffin sections were prepared for H\&E staining, and $3 \mu \mathrm{m}$ thick paraffin sections were prepared for immunohistochemical staining, including caspase-3, survivin, Bax, and Bcl-2, to assess the pathological and immunological changes in tumor tissue, respectively. The used instruments were Leica
RM 2245 paraffin machine, Leica HI1210 fishing machine, Leica HI1220 booth machine, Leica EG1150H embedding machine (Leica Microsystems, Wetzlar, Germany), Olympus BX51 microscope (Olympus Corporation, Tokyo, Japan), and Motic image analysis system (Motic Image Advanced 3.2; Motic Industrial Group Co., Ltd., Xiamen, People's Republic of China).

\section{Histopathological and biochemical analyses of organs}

Besides tumor tissues, other major internal organs and tissues, that is, heart, liver, spleen, lung, kidney, thymus, and sternum, were also collected simultaneously. The organs from healthy mice were also isolated as a normal control. Each organ was divided into two parts: 1) one part except sternum was fixed with 4\% ( $W / V)$ PBS-buffered paraformaldehyde for histopathological analyses through H\&E staining with a similar protocol as tumor tissue; 2) the other part was prepared to detect the organ function-related biochemical indicators, including CK-MB, LDH, ALT, AST, BUN, and $\mathrm{Cr}$, by ELISA in accordance with the instructions of manufacturers. The histopathological and immunohistochemical results were detected by Olympus BX51 microscope and analyzed with Motic Image Advanced 3.2.

\section{Histopathological assays of sternums and detections of marrow micronucleus cell rates}

In addition, a part of sternums of BALB/c mice were placed in $10 \%(V / V)$ formic acid-formalin solution, decalcified, and fixed for 10 days. The data from normal mice were used as a normal control. And then, the tissues were dehydrated, followed by clearing, wax infiltration, and embedding. Four paraffin sections of sternums with a thickness of $5 \mu \mathrm{m}$ for each sternum were collected with an interval of $50.0 \mu \mathrm{m}$ for $\mathrm{H} \& \mathrm{E}$ staining. The marrow micronucleus cell rate (MMCR) was evaluated from $H \& E$ section.

\section{White blood cell count and blood biochemical analyses}

On Day 25, $20.0 \mu \mathrm{L}$ of anticoagulated blood from each mouse through enucleation method was taken to count white blood cells (WBCs). The other $300.0 \mu \mathrm{L}$ of blood without anticoagulant was centrifuged at 3,000 rpm for 10 minutes. The serum was collected to detect the clinical biochemical parameters, consisting of CK-MB, LDH, ALT, AST, BUN, and $\mathrm{Cr}$, by ELISA according to the instructions of manufacturers. The data from normal mice were used as control. 


\section{Statistical analyses}

All tests were carried out at least three times, and the data were expressed as mean \pm standard deviation (SD). Statistical analysis was performed using SPSS 13.0 for Windows (SPSS Inc., Chicago, IL, USA), $P<0.05$ was considered statistically significant, and $P<0.01$ and $P<0.001$ were considered significant differences.

\section{Results and discussion Characterizations of NG/DOX}

In this study, the prepared reduction-responsive nanogel was composed of hydrophilic PEG shell and hydrophobic disulfide-crosslinked $\mathrm{P}\left(\mathrm{LP}_{12}-\mathrm{co}-\mathrm{LC}_{2}\right)$ core. DOX, a model hydrophobic antitumor drug, was loaded into the core of nanogel through a successive dispersion and dialysis technique (Figure 1). The drug loading content and drug loading efficiency of NG/DOX were calculated to be $10.2 \mathrm{wt} \%$ and $56.8 \mathrm{wt} \%$, respectively. The $R_{\mathrm{h}}$ of NG/DOX was detected to be $56.1 \pm 3.5 \mathrm{~nm}$. Apparently, the appropriate size is conducive to the selective accumulation of NG/DOX in the tumor site through the EPR effect. ${ }^{24,25}$

\section{In vivo biocompatibility and distribution}

The assessments of biocompatibility and biodistribution are necessary to determine whether a new drug formulation is suitable for clinical application or not. ${ }^{22}$ In this work, the biocompatibility of NG/DOX was measured by MTD assay. In addition, the detections of DOX fluorescence intensities in various tissues were strictly accomplished to verify the selective intratumoral accumulation of NG/DOX.

To determine the biocompatibility of nanogel, free DOX $\cdot \mathrm{HCl}$, and $\mathrm{NG} / \mathrm{DOX}$, the MTDs were estimated by a single IV injection to healthy Kunming mice (Figure 3). In practice, the body weights and survival rates of mice were monitored for 10 days after the IV injection of nanogel at the doses of $100.0 \mathrm{mg}(\mathrm{kg} \mathrm{BW})^{-1}, 300.0 \mathrm{mg}(\mathrm{kg} \mathrm{BW})^{-1}$, and $500.0 \mathrm{mg}(\mathrm{kg} \mathrm{BW})^{-1}$, or free DOX $\cdot \mathrm{HCl}$ or NG/DOX at the doses of $5.0 \mathrm{mg}(\mathrm{kg} \mathrm{BW})^{-1}, 10.0 \mathrm{mg}(\mathrm{kg} \mathrm{BW})^{-1}$, and $15.0 \mathrm{mg}$ $(\mathrm{kg} \mathrm{BW})^{-1}$ DOX$\cdot \mathrm{HCl}$ equivalents. As shown in Figure 3, no weight losses and deaths were detected in the nanogel groups with the doses up to $500.0 \mathrm{mg}(\mathrm{kg} \mathrm{BW})^{-1}$, indicating their good biocompatibility in vivo. However, significant losses of body weight and deaths were monitored in the free $\mathrm{DOX} \cdot \mathrm{HCl}$ groups at the doses of $10.0 \mathrm{mg}(\mathrm{kg} \mathrm{BW})^{-1}$ and $15.0 \mathrm{mg}(\mathrm{kg} \mathrm{BW})^{-1}$ from Day 4 postinjection. The average body weight loss of mice treated with $15.0 \mathrm{mg}(\mathrm{kg} \mathrm{BW})^{-1}$ free $\mathrm{DOX} \cdot \mathrm{HCl}$ was $16.6 \%$, indicating serious side effects. ${ }^{22}$ At the same time, the 10-day survival rate was $40 \%$ at a dose of $15 \mathrm{mg}(\mathrm{kg} \mathrm{BW})^{-1}$.
As expected, the nanogel-encapsulated drug exhibited decreased systemic toxicity with less body weight loss and a significant prolongation of survival time at all test doses. The MTDs of all the determined formulations were estimated based on the threshold, at which all animals survived and the loss of body weight was $<15 \%$ within 10 days postinjection. ${ }^{23}$ The MTD of free DOX $\cdot \mathrm{HCl}$ was determined to be 6.0-7.5 mg $(\mathrm{kg} \mathrm{BW})^{-1}$, which was in accordance with that of previous studies ${ }^{26,27}$ while that of NG/DOX was close to or over $10.0 \mathrm{~m} \mathrm{~kg}^{-1}$. The result confirmed the improved security of NG/DOX compared with free DOX $\cdot \mathrm{HCl}$.

After the detection of MTD, the mice were sacrificed, and the major internal organs (ie, heart, liver, spleen, lung, and kidney) were collected and weighted. The organ indices were calculated by the weight ratios of organs $(\mathrm{mg})$ and whole body (g). For all the indices of various organs, significantly decreased spleen index was observed for the free $\mathrm{DOX} \cdot \mathrm{HCl}$ groups as the DOX $\cdot \mathrm{HCl}$ dose increased from $10.0 \mathrm{mg}(\mathrm{kg} \mathrm{BW})^{-1}$ to $15.0 \mathrm{mg}(\mathrm{kg} \mathrm{BW})^{-1}$. The main reason was that the massive cells of spleen appeared dead after the treatment of DOX. ${ }^{28}$ Fortunately, no decrease of spleen indices was observed in the NG/DOX groups at all the test doses up to $15.0 \mathrm{mg}(\mathrm{kg} \mathrm{BW})^{-1}$. To face the reality, the dose intensification of DOX in a real clinical setting is significant as it may allow patients to receive a full dose of chemotherapy without the severe dose-dependent toxicities. These results suggest that the MTD of DOX can be upregulated through being loaded into nanogel, resulting in the stimuli-responsive drug release and reduced systemic toxicity simultaneously.

The tissue distribution of antitumor drug associates with both the efficacy of tumor suppression and security in vivo. In this study, the tissue distribution of DOX in vivo was qualitatively detected by the fluorescence imaging of isolated tumors and major internal organs, and semi-quantitatively analyzed by Maestro ${ }^{\mathrm{TM}} 2.4$ software. As shown in Figure 4A, $\mathrm{NG} / \mathrm{DOX}$ accumulated at tumor sites more efficiently than free DOX. $\mathrm{HCl}$ at the doses of both $3.0 \mathrm{mg}(\mathrm{kg} \mathrm{BW})^{-1}$ and $6.0 \mathrm{mg}(\mathrm{kg} \mathrm{BW})^{-1}$ at 12 hours postinjection. The results should be attributed to the EPR effect of NG/DOX toward tumor tissue. It should be noted that doubling the dose did not result in a doubling of the accumulated amount of DOX formulations, indicating the nonlinear correlation between dose and intratumoral accumulation of drug. In addition to tumor tissue, a relatively strong DOX fluorescence was observed in both kidney and liver for both the DOX formulations. The phenomenon showed that the drugs were mainly metabolized by kidney and liver. Furthermore, the DOX fluorescence intensities regarding the kidney and liver of free DOX $\cdot \mathrm{HCl}$ 

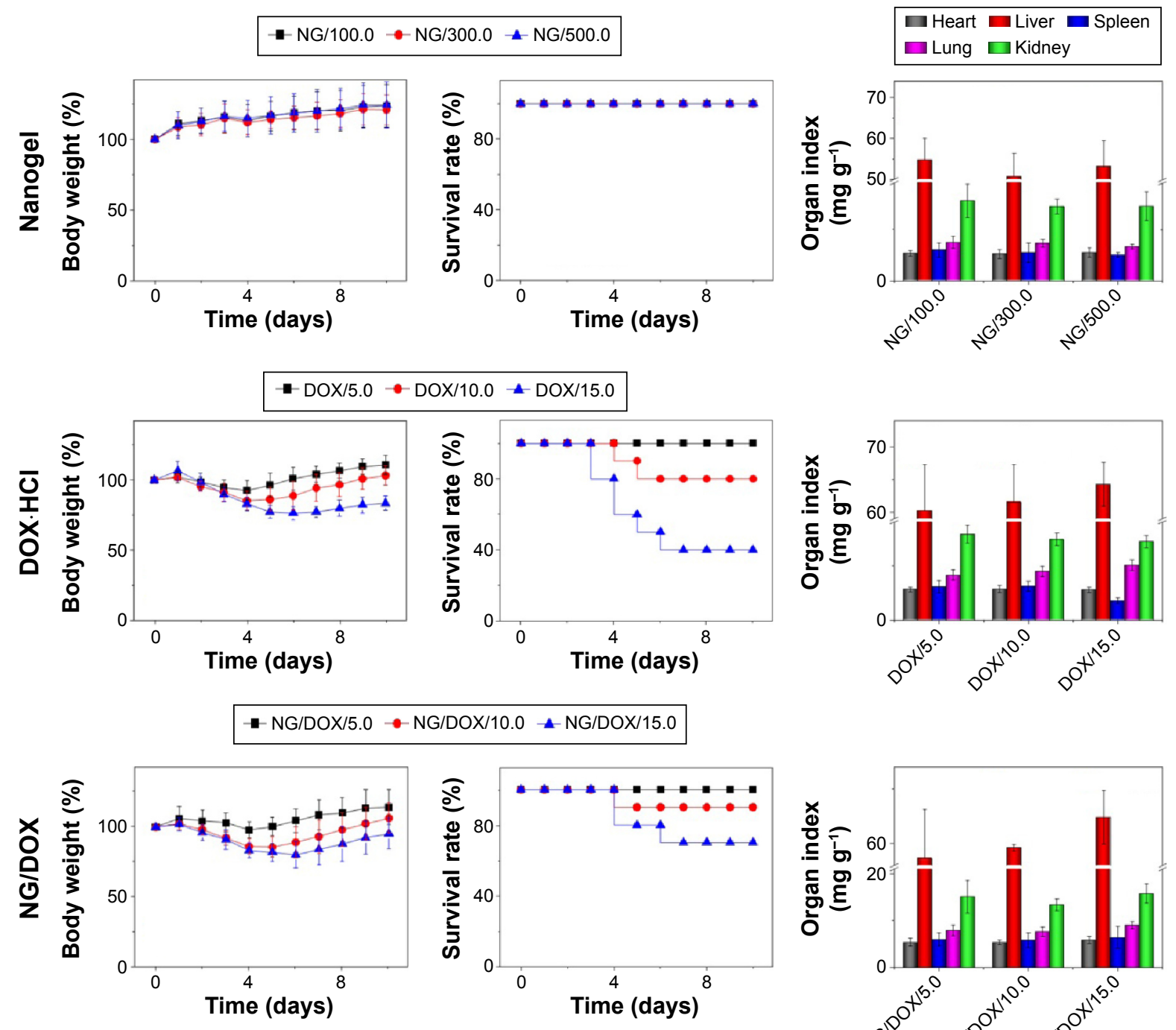

$\mathrm{NG} / \mathrm{DOX} / 10.0 \_\mathrm{NG} / \mathrm{DOX} / 15.0$
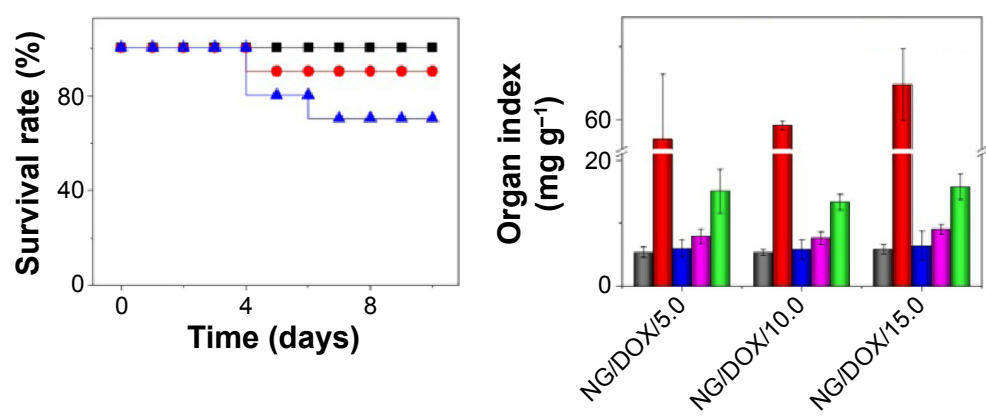

Figure 3 Percent body weights, survival rates, and organ indices in MTD detections.

Notes: Percent body weights, survival rates, and organ indices of Kunming mice after disposable intravenous injection of NG at doses of I00.0 mg (kg BW) ${ }^{-1}, 300.0 \mathrm{mg}(\mathrm{kg} B W)^{-1}$, and $500.0 \mathrm{mg}(\mathrm{kg} \mathrm{BW})^{-1}$, and DOX.HCl and NG/DOX at equivalent DOX.HCl doses of $5.0 \mathrm{mg}(\mathrm{kg} \mathrm{BW})^{-1}, 10.0 \mathrm{mg}(\mathrm{kg} \mathrm{BW})^{-1}$, and I5.0 mg (kg BW) ${ }^{-1}$. The statistical data are presented as a mean \pm SD.

Abbreviations: BW, body weight; DOX, doxorubicin; DOX.HCl, doxorubicin hydrochloride; MTD, maximum tolerated dose; NG, nanogel; NG/DOX, DOX-loaded nanogel; SD, standard deviation.

groups were higher than those of NG/DOX groups in any one dose. The enhanced accumulation of free drug might result in the undesirable nephrotoxicity and hepatotoxicity.

The semi-quantitative fluorescence intensities of DOX in tumors and main visceral organs at 12 hours postinjection were evaluated and shown in Figure 4B. The results indicated that the average signals of NG/DOX groups were $\sim 1.7$ times higher than those of free DOX $\cdot \mathrm{HCl}$ groups for each individual dose (ie, $3.0 \mathrm{mg}[\mathrm{kg} \mathrm{BW}]^{-1}$ or $6.0 \mathrm{mg}[\mathrm{kg} \mathrm{BW}]^{-1} ; P<0.001$ ). More interestingly, the accumulation of NG/DOX obviously downregulated to 0.8 -fold and 0.6 -fold in kidney and 0.9-fold and 0.7 -fold in liver at the DOX. $\mathrm{HCl}$ doses of $3.0 \mathrm{mg}$ $(\mathrm{kg} \mathrm{BW})^{-1}$ and $6.0 \mathrm{mg}(\mathrm{kg} \mathrm{BW})^{-1}$, respectively, in comparison with that of free $\mathrm{DOX} \cdot \mathrm{HCl}(P<0.001)$. The above data indicated that NG/DOX exhibited the enhanced intratumoral accumulation and decreased metabolism at normal organs as compared with free DOX $\cdot \mathrm{HCl}$, which might mean the high antitumor efficacy and security in vivo.

\section{In vivo evaluation of antitumor efficacy}

Generally, the efficacy and security of chemotherapy are a contradiction, that is, a higher antitumor efficacy often associates with more serious side effects..$^{29,30}$ Therefore, the efficacy and security in vivo are the two most critical performances of antitumor drug formulations. The two aforementioned properties of any newly developed 
A

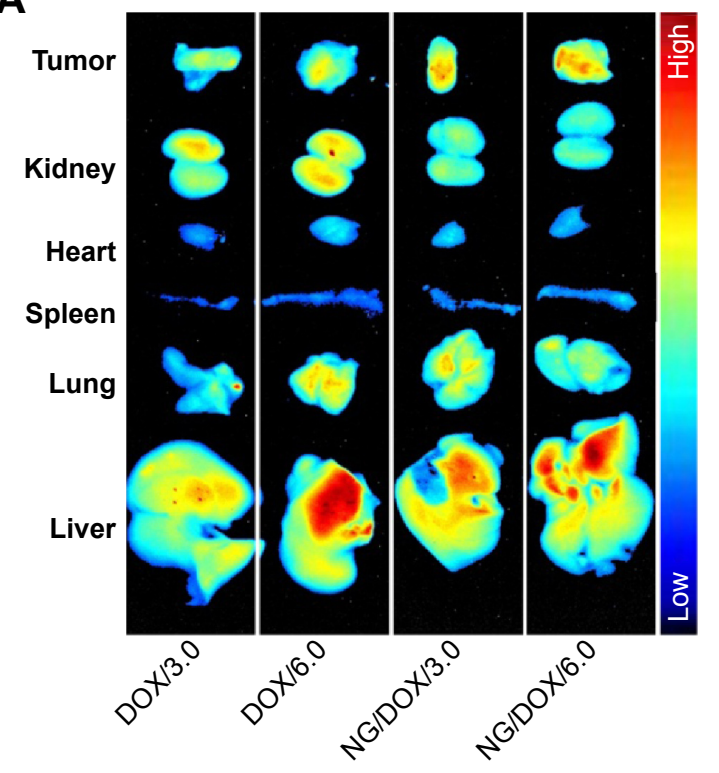

B

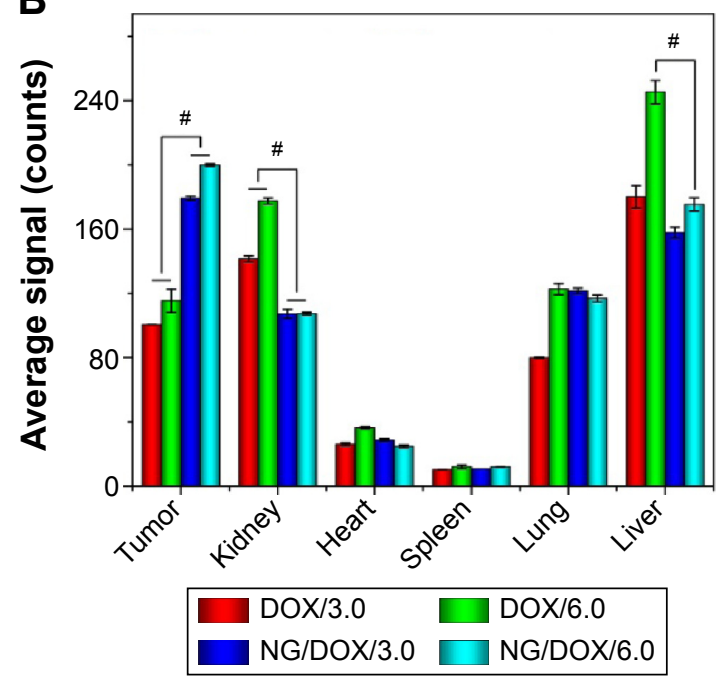

Figure 4 Tissue distribution.

Notes: Ex vivo DOX fluorescence images (A) and semi-quantitatively analyzed average fluorescence intensities (B) of tumors and major visceral organs (ie, kidney, heart, spleen, lung, and liver) isolated at 12 hours postinjection of free DOX. $\mathrm{HCl}$ or $\mathrm{NG} / \mathrm{DOX}$ at a dose of $3.0 \mathrm{mg}$ or $6.0 \mathrm{mg} \mathrm{DOX} \cdot \mathrm{HCl}$ equivalent per kilogram body weight toward $B A L B / c$ nude mice bearing HepG2 tumors. The statistical data are represented as mean $\pm S D(n=3 ; \#<0.001)$.

Abbreviations: DOX, doxorubicin; DOX.HCl, doxorubicin hydrochloride; NG/DOX, DOX-loaded nanogel; SD, standard deviation.

formulations should be systematically assessed before clinical application.

The detections of tumor inhibition efficacies toward tumor-xenografted mouse models are a generic approach to judge the antitumor capabilities of nanoscale drug delivery systems. ${ }^{31,32}$ In this work, the excellent antitumor efficacy of NG/DOX was revealed against $\mathrm{H} 22$ hepatoma-bearing $\mathrm{BALB} / \mathrm{c}$ mouse models. In practice, the tumor volumes were real-time monitored in the process of treatment, and the histopathological and immunohistochemical assessments of tumor tissue sections after treatments were subsequently performed. As soon as the tumor volume grew up to approximately $400 \mathrm{~mm}^{3}$, the treatment of NS as control or free DOX $\cdot \mathrm{HCl}$ or $\mathrm{NG} / \mathrm{DOX}$ with $3.0 \mathrm{mg}$ or $6.0 \mathrm{mg} \mathrm{DOX} \cdot \mathrm{HCl}$ equivalent per $\mathrm{kg}$ body weight was initiated by IV injection for four times every 5 days. The doses of DOX were chosen based on the MTD of free DOX $\cdot \mathrm{HCl}\left(\sim 6.0 \mathrm{mg}[\mathrm{kg} \mathrm{BW}]^{-1}\right)$ in order to ensure the survival of mice and good treatment efficacy. The tumor volumes were detected daily from the second day after inoculation, which was defined as Day 1. The first treatment was performed on Day 7. As shown in Figure 5, no significant difference in the tumor volumes was observed for all the test groups before Day $11(P>0.05)$. From Day 11, the differences among the antitumor efficacies of all groups were observed. The tumors of control group grew out of control, and their average volume increased three times and reached to $\sim 3,500 \mathrm{~mm}^{3}$ in the next 2 weeks. The tumors were suppressed to different extents through the treatments with various DOX formulations. In detail, the tumor of DOX/3.0 group grew slowly, while NG/DOX/3.0 inhibited tumor at a constant volume with the same dosage of $3.0 \mathrm{mg}(\mathrm{kg} \mathrm{BW})^{-1}$. Furthermore, the increased dosage from $3.0 \mathrm{mg}(\mathrm{kg} \mathrm{BW})^{-1}$ to $6.0 \mathrm{mg}(\mathrm{kg} \mathrm{BW})^{-1}$ induced the improved antitumor efficacy. Both DOX/6.0 and NG/DOX/6.0 reduced

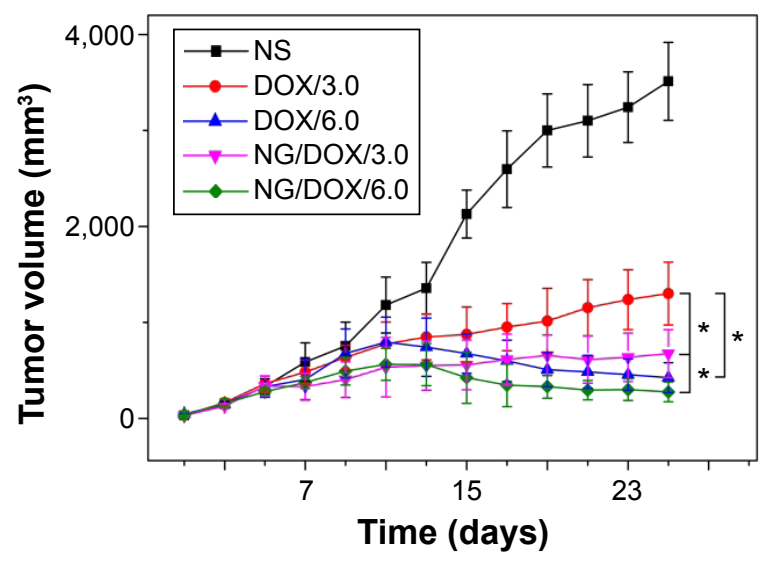

Figure 5 In vivo antitumor efficacies.

Notes: In vivo antitumor efficacies of NS as control, and free DOX.HCl and NG/ DOX at a dosage of 3.0 and $6.0 \mathrm{mg} \mathrm{DOX} \cdot \mathrm{HCl}$ equivalent per $\mathrm{kg}$ body weight toward $\mathrm{H} 22$ hepatoma-xenografted BALB/c mouse models. Each set of data is represented as mean $\pm S D(n=10 ; * P<0.001)$.

Abbreviations: DOX, doxorubicin; DOX.HCl, doxorubicin hydrochloride; NG/DOX, DOX-loaded nanogel; NS, normal saline; SD, standard deviation. 
the volumes of tumors. More fascinatingly, NG/DOX/6.0 exhibited the enhanced antitumor efficacy compared with DOX/6.0 $(P<0.05)$. The improved tumor inhibition capability of NG/DOX in vivo at above two dosages should be attributed to the selective intratumoral accumulation through the EPR effect and targeting intracellular reduction-triggered DOX release. ${ }^{33,34}$

Furthermore, a higher antitumor efficacy of NG/DOX was confirmed by both histopathological and immunohistochemical analyses of tumor tissues. After all the treatments on Day 25 , the mice were sacrificed by cervical dislocation, and the tumors were isolated for $\mathrm{H} \& \mathrm{E}$ and immunohistochemical staining. As shown in Figure 6, the H\&E staining of tumor tissue in the control group revealed the universal mitosis and small area of hemorrhagic necrosis, which indicated the vigorous growth of tumor. The necrotic manifestations were nuclear enrichment and/or fragmentation, the dissolution of tumor cells, and even the formation of a lot of bleeding area. As expected, all the treatments of DOX formulations caused the different levels of tumor suppression. They specifically expressed in the decreased mitosis and upregulated areas of hemorrhage and necrosis. The apparent necrosis areas of all the test formulations were in the following sequence: $\mathrm{NG} /$ $\mathrm{DOX} / 6.0>\mathrm{DOX} / 6.0>\mathrm{NG} / \mathrm{DOX} / 3.0>\mathrm{DOX} / 3.0$. In addition, the semi-quantitative data were calculated by Motic Image Advanced 3.2. As shown in Figure 7A, the NG/DOX groups had 1.9-fold and 1.4-fold larger necrosis area than the free DOX $\cdot \mathrm{HCl}$ groups at the dosages of $3.0 \mathrm{mg}(\mathrm{kg} \mathrm{BW})^{-1}$ and $6.0 \mathrm{mg}(\mathrm{kg} \mathrm{BW})^{-1}$, respectively. The result indicated that the degrees of tumor necrosis were consistent with the levels of tumor inhibition.

In recent years, the relationship between macroscopic tumor volumes and microscopic immunohistochemical morphologies attracts increasing attention. ${ }^{22,35,36}$ In this study, four kinds of immunohistochemical staining, that is, caspase-3, survivin, Bax, and Bcl-2, were carried out simultaneously for auxiliary assessment of the different antitumor efficacies of all the test formulations and for exploring the antitumor mechanisms from the perspective of genetics (Figure 6). Cell apoptosis is mediated by different signaling pathways, genes,

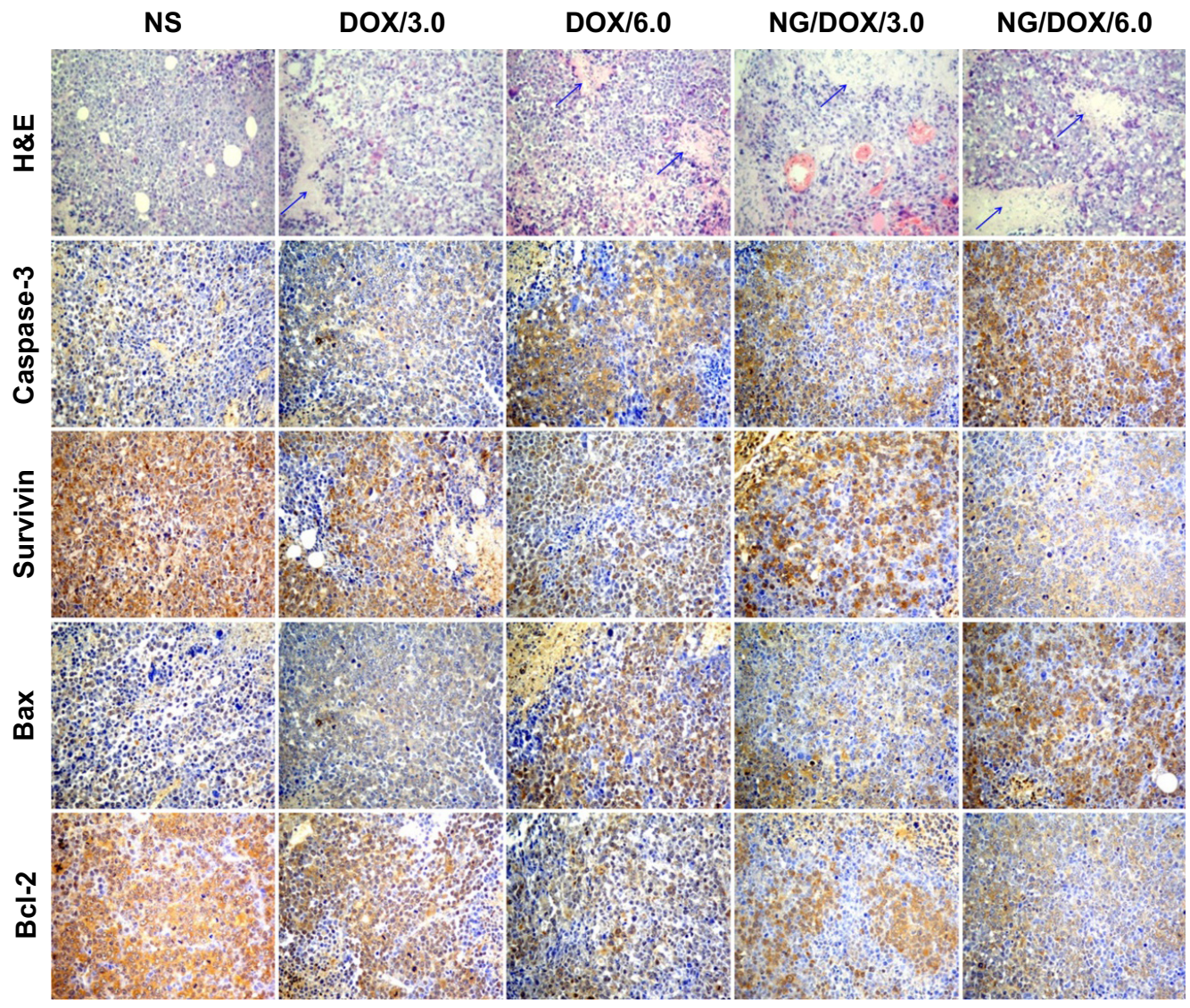

Figure 6 Histopathological and immunohistochemical analyses.

Notes: Histopathological (ie, H\&E) and immunohistochemical (ie, caspase-3, survivin, Bax, and Bcl-2) analyses of tumor tissues sections after treatment of NS as control, or free DOX. $\mathrm{HCl}$ or NG/DOX at a dosage of $3.0 \mathrm{mg}$ or $6.0 \mathrm{mg} \mathrm{DOX} \cdot \mathrm{HCl}$ equivalent per kilogram body weight. The arrows indicate the typical necrotic area. Magnification: $200 \times$. Abbreviations: DOX, doxorubicin; DOX.HCl, doxorubicin hydrochloride; H\&E, hematoxylin and eosin; NG/DOX, DOX-loaded nanogel; NS, normal saline. 

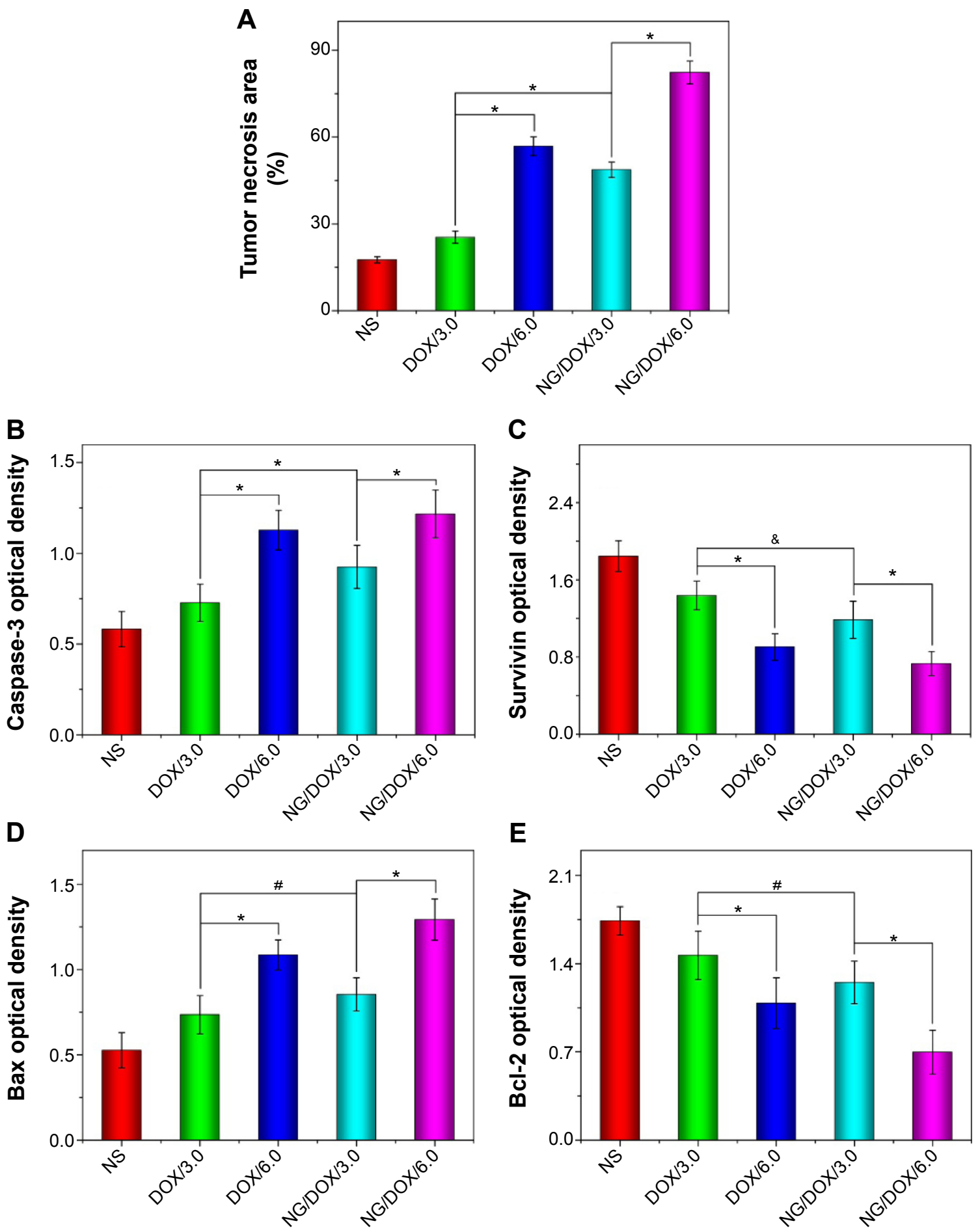

Figure 7 Semi-quantitative analyses of histopathological and immunohistochemical results.

Notes: Tumor necrotic area from H\&E (A), and relative optical densities of tumor sections from caspase-3 (B), survivin (C), Bax (D), and Bcl-2 (E) after treatment with $\mathrm{NS}$ as control, or free DOX.HCl or NG/DOX at a dosage of $3.0 \mathrm{mg}$ or $6.0 \mathrm{mg}$ DOX. $\mathrm{HCl}$ equivalent per $\mathrm{kg}$ body weight. Each set of data is represented as mean \pm SD $\left(\mathrm{n}=10 ;{ }^{*} P<0.05,{ }^{\&} \mathrm{P}<0.01, * \mathrm{P}<0.001\right)$.

Abbreviations: DOX, doxorubicin; DOX.HCl, doxorubicin hydrochloride; H\&E, hematoxylin and eosin; NG/DOX, DOX-loaded nanogel; NS, normal saline; SD, standard deviation.

and proteins. Among them, caspase family is considered to be a core executor during apoptosis process. ${ }^{37}$ The activation of caspase-3, an apoptosis-promoting factor, is the key approach in numerous stimuli-induced apoptosis. ${ }^{38}$ Survivin belongs to the inhibitors of apoptosis protein families and is highly expressed in most tumor tissues and transformed cells. ${ }^{39}$ In addition, survivin is involved in the development of tumors and shows a potential value as a tumor marker. ${ }^{40}$ Survivin 
inhibits cell apoptosis by two pathways: 1) it directly inhibits the activity of caspase-3, and 2) it can block the activation of caspase- 3 to inhibit the apoptosis of cells indirectly. ${ }^{41}$ As shown in Figure 6, all the sections in the DOX-formulationtreated groups exhibited certain elevated levels of caspase-3 and some decreased degrees of survivin compared with those of control group. The regulations of both caspase- 3 and survivin were amplified as the dosage increasing from $3.0 \mathrm{mg}(\mathrm{kg} \mathrm{BW})^{-1}$ to $6.0 \mathrm{mg}(\mathrm{kg} \mathrm{BW})^{-1}$. More interestingly, at both dosages, NG/DOX induced the enhanced cell apoptosis along with the upregulated caspase- 3 and the downregulated survivin in comparison with free DOX $\cdot \mathrm{HCl}$. Similar to H\&E, the semi-quantitative optical densities of both caspase-3 and survivin were calculated by an image analysis system of Motic Image Advanced 3.2. As depicted in Figure 7B, the NG/DOX/3.0 group showed 1.6 and 1.3 times caspase-3 signals than $\mathrm{NS}$ as control and DOX/3.0, respectively. NG/DOX/6.0 and DOX/6.0 exhibited 1.3 and 1.6 times signals of caspase-3 compared with $\mathrm{NG} / \mathrm{DOX} / 3.0$ and $\mathrm{DOX} / 3.0$, respectively. In contrast, NG/DOX exhibited the reduced data of survivin compared with free DOX $\mathrm{HCl}$. In detail, NG/DOX/3.0 and NG/DOX/6.0 displayed both 0.8 -fold survivin signals of DOX/3.0 and DOX/6.0, respectively (Figure 7C). The results coincided with the previously discussed antitumor efficacies and histopathological analyses, which demonstrated the improved tumor inhibition capability of NG/DOX with a dose-dependent feature.

Furthermore, Bax and Bcl-2 are another pair of factors in the process of cell apoptosis. ${ }^{42}$ Bax promotes cell apoptosis, while Bcl-2 inhibits cell apoptosis. The two factors can regulate the state of cells in tumor tissue by the modulation of cell apoptosis. Similar to the results of caspase- 3 and survivin, the elevated Bax and reduced Bcl-2 were observed in all the groups treated with various DOX formulations with respect to the control group. Both the increase of dosage and the encapsulation with reduction-responsive nanogel could upregulate the expression of Bax and downregulate the signal of Bcl-2 in tumor tissues treated with various DOX formulations (Figure 6). With the same approach, the semiquantitative events of Bax and Bcl-2 were assessed. As shown in Figure 7D, NG/DOX exhibited both 1.2 times expression of Bax than free $\mathrm{DOX} \cdot \mathrm{HCl}$ at the dosages of $3.0 \mathrm{mg}$ $(\mathrm{kg} \mathrm{BW})^{-1}$ and $6.0 \mathrm{mg}(\mathrm{kg} \mathrm{BW})^{-1}$, respectively. Conversely, NG/DOX/3.0 and NG/DOX/6.0 displayed 0.2-fold and 0.4fold decrease of Bcl-2 signals compared with DOX/3.0 and DOX/6.0, respectively. The results revealed that NG/DOX can upregulate the expression of pro-apoptotic genes and suppress the expression of anti-apoptotic genes with a higher efficiency compared with free DOX $\cdot \mathrm{HCl}$. Thereby, the smart nanogelloaded antitumor drug could promote tumor cell apoptosis and then inhibit tumor growth with fascinating potential for clinical application compared with the free one.

\section{Assessment of security in vivo}

At present, almost all the formulations of antitumor drugs in clinic exhibited more or less side effects. Moreover, the excellent tumor suppression efficacy is always accompanied by the serious side effects. ${ }^{29,30}$ As a typical example, the treatment with DOX always causes serious acute cardiotoxicity and nephrotoxicity. ${ }^{43}$ Therefore, the in vivo security of newly designed antitumor drug formulations is another important indicator for the future clinical applications. In this work, the systematic safety assessments were performed through the surveillances of body weights in the course of treatments, analyses of pathological morphologies of various organs after therapeutics, counts of marrow micronucleus cell rate (MMCR) and WBC, and statistics of clinical biochemical parameters in the corresponding organs or serum.

The body weights of all H22 hepatoma-xenografted mice were real-time monitored for 25 days from the second day after inoculation (Figure 8). As shown in Figure 8, the body weights of mice from each treated group exhibited consistent growth trend, and there was no significant difference between any two groups in the beginning $1-7$ days $(P>0.05)$. During the treatment stage, that is, Days 7-11, the body weights of all the mice decreased synchronously with no significant difference $(P>0.05)$. Afterward, the body weights of NG/DOX/3.0

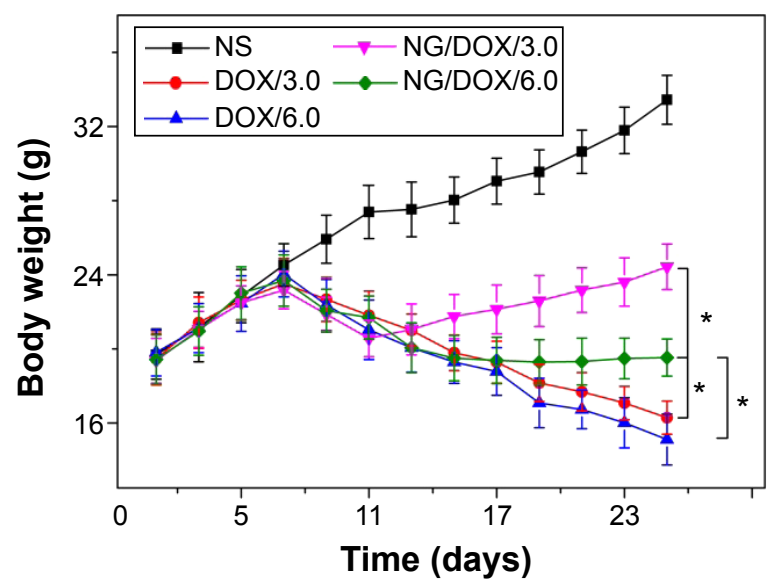

Figure 8 Body weight changes.

Notes: Body weight changes of $\mathrm{H} 22$ hepatoma-bearing BALB/c mice in the course of treatment with NS as control, or free DOX.HCl or NG/DOX at a dosage of $3.0 \mathrm{mg}$ or $6.0 \mathrm{mg} \mathrm{DOX} \cdot \mathrm{HCl}$ equivalent per $\mathrm{kg}$ body weight. Each set of data is represented as mean $\pm S D(n=10 ; * P<0.001)$.

Abbreviations: DOX, doxorubicin; DOX. $\mathrm{HCl}$, doxorubicin hydrochloride; NG/ DOX, DOX-loaded nanogel; NS, normal saline; SD, standard deviation. 
group showed a slow upward trend on Days 11-25, and there was significant difference compared with all the other groups $(P<0.01)$. Within a time interval of Day 11-17, the body weights of mice of NG/DOX/6.0, DOX/3.0, and DOX/6.0 groups continued the downward trend, and no significant difference among the groups was observed $(P>0.05)$. More interestingly, the mice body weights of NG/DOX/6.0 group stayed in plateau phase ( $19.5 \mathrm{~g})$ during the final 8 days, that is, from Day 17 to 25 , and they were significantly different with those treated with free DOX. $\mathrm{HCl}$ at $3.0 \mathrm{mg}(\mathrm{kg} \mathrm{BW})^{-1}$ and $6.0 \mathrm{mg}(\mathrm{kg} \mathrm{BW})^{-1}(P<0.05)$. However, in the final stage (17-25 days), the body weights of mice in the DOX/3.0 and DOX/6.0 groups synchronously decreased to $16.3 \mathrm{~g}$ and $15.1 \mathrm{~g}$ on Day 25, respectively, which were lower than the initial weight $(\sim 19.5 \mathrm{~g})$. The relevance between treatments with various drug formulations and the body weight changes of experimental animals directly indicated the security along with the efficacy. The treatments with a dosage of $6.0 \mathrm{mg}$ $(\mathrm{kg} \mathrm{BW})^{-1}$ induced more severe weight loss compared with those at a dosage of $3.0 \mathrm{mg}(\mathrm{kg} \mathrm{BW})^{-1}$. The result indicated the dose-dependent side effects of DOX. In addition, compared with the continuously declined body weights of mice in the free $\mathrm{DOX} \cdot \mathrm{HCl}$ groups, the promptly stopped body weight loss of mice in the NG/DOX groups revealed the improved security of DOX after being loaded with the reduction-responsive nanogel. The low toxicity of NG/DOX on mice should be attributed to the directional intratumoral accumulation through the EPR effect and the subsequent selective intracellular drug release.

As mentioned above, the multiple IV injections of highly toxic antineoplastic agents always cause severe organ damage. ${ }^{44,45}$ As shown in Figure 9, the histopathological structure of each organ was detected by pathological examination. Compared with NG/DOX, the treatment of free DOX. $\mathrm{HCl}$ at both doses of $3.0 \mathrm{mg}(\mathrm{kg} \mathrm{BW})^{-1}$ and $6.0 \mathrm{mg}(\mathrm{kg} \mathrm{BW})^{-1}$ resulted in various damage toward heart, liver, and kidney diagnosed from their abnormal histopathological morphologies. Surprisingly, the thymuses of all the tumor-bearing mice without or with treatments showed some different pathological morphologies compared with that of normal mouse. In detail, thymus showed notable atrophy, and the boundary between cortex and medulla of thymus was unclear in the NS as control group. In both DOX/3.0 and DOX/6.0 groups, thymic corpuscles reduced or even disappeared. In contrast, the pathological topographies of both NG/DOX/3.0 and NG/DOX/6.0 were similar to the normal one. More fascinatingly, the tumor metastasis was observed in the NS as control group rather than all the treated groups with various DOX formulations. It indicated that the appropriate chemotherapy can decrease the risk of tumor metastasis to some extent.

The external factors, such as toxic small molecules and radioactive substances, always cause the loss or damage of chromosome, which induces the increase of MMCR ${ }^{46}$ Therefore, MMCR can reflect the body injury of chemotherapy drugs. As shown in Figure 9, the bone marrow mononuclear cells were observed in the H\&E-stained marrow section from each group. The MMCRs were figured out from the histopathological sections (Figure 10A). The MMCRs of H22 hepatoma-xenografted mice after all the treatments were significantly elevated with respect to those of normal mice. The dose-correlated increase of MMCR was observed in the mice of both free $\mathrm{DOX} \cdot \mathrm{HCl}$ and $\mathrm{NG} / \mathrm{DOX}$ groups $(P<0.05)$, while the treatment of free $\mathrm{DOX} \cdot \mathrm{HCl}$ exhibited significantly greater upregulation of MMCR than that of NG/DOX $(P<0.01)$. The results revealed that the damage of DOX formulations to the body was dose-dependent, and the controlled delivery could downregulate the injury to some extent.

According to the previously reported results, the count of WBC can indirectly reflect the impact of chemotherapy on the immune status. ${ }^{47}$ As depicted in Figure 10B, the WBC count in the NS as control group was significantly higher than the other groups. It indicated that the existence of tumor induced the severe inflammation, while the treatments with various DOX formulations eliminated the inflammation to some extent. The results indirectly proved the safety and even efficacy of the treatments with both free DOX $\cdot \mathrm{HCl}$ and NG/DOX.

In clinic, the heart-associated (eg, CK-MB and LDH), liver-associated (eg, ALT and AST), and kidney-associated (eg, BUN and Cr) parameters are usually detected to determine the states of appropriate organs. ${ }^{48}$ Generally, a higher level of above detection index relates to a more serious injury of corresponding organ. In this study, the changes of characteristic biochemical indices (ie, CK-MB, LDH, ALT, AST, BUN, and $\mathrm{Cr}$ ) in the isolated corresponding organs (Figure 11) and serum (Figure 12) were detected via the commercial ELISA kits to further confirm the excellent security of all the treatments with various DOX formulations. As shown in Figures 11 and 12, the dose-dependent increase of both CK-MB and LDH levels in the free $\mathrm{DOX} \cdot \mathrm{HCl}$ groups indicated the severe heart damage after treatment. Fortunately, the levels of heart-related indices in the NG/DOX groups were comparable with those of normal mice, demonstrating the decreased cardiotoxicity of DOX after encapsulation with nanogel. In addition, all the other clinical parameters of all the test DOX formulation groups 


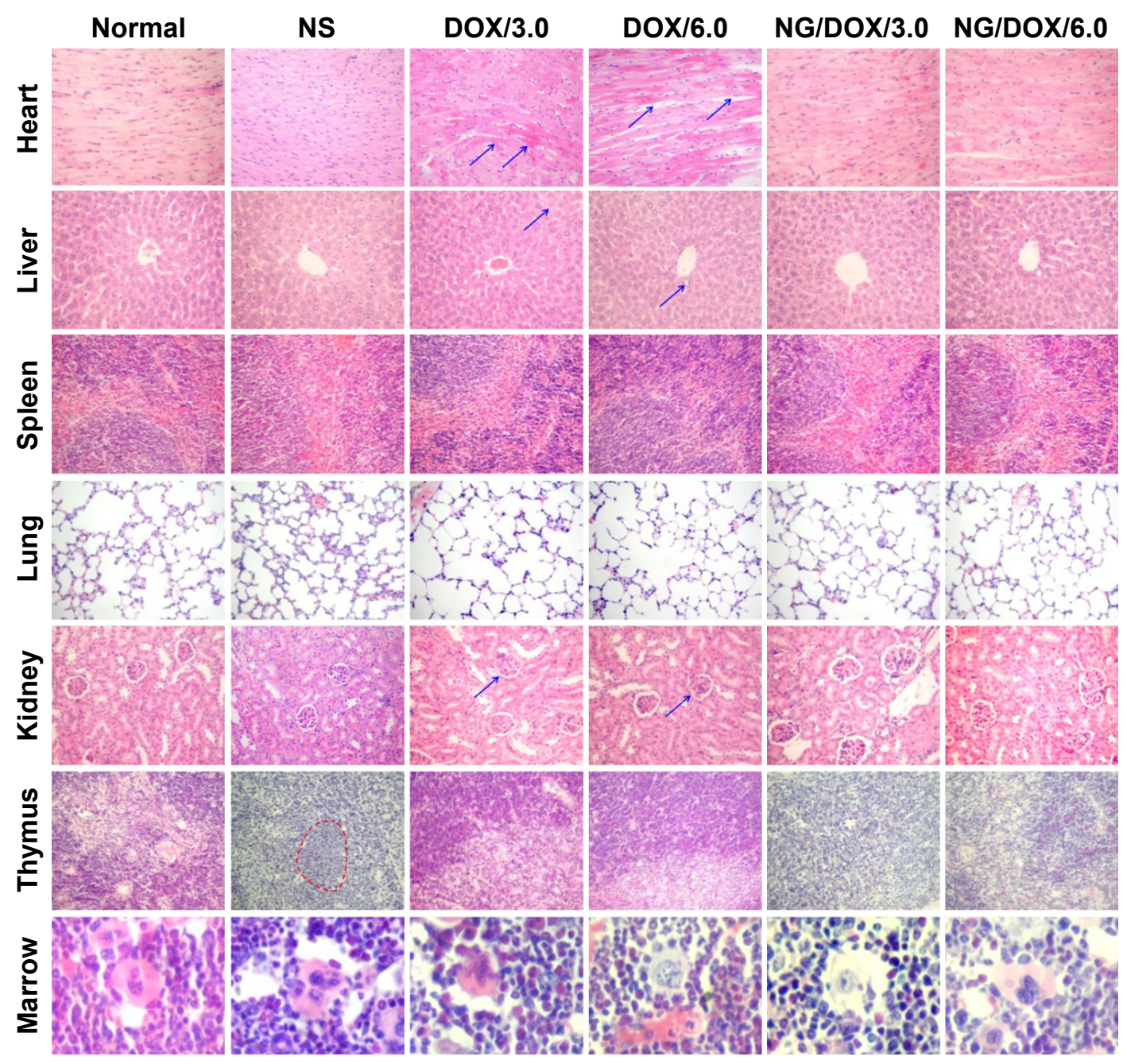

Figure 9 Histopathology analyses of visceral organ sections.

Notes: Histopathology analyses of visceral organ sections, that is, heart, liver, spleen, lung, kidney, thymus, and marrow, from normal mice, or H22 hepatoma-xenografted $\mathrm{BALB} / \mathrm{c}$ mice after treatment with $\mathrm{NS}$ as control, or free DOX. $\mathrm{HCl}$ or NG/DOX at a dosage of $3.0 \mathrm{mg}$ or $6.0 \mathrm{mg} \mathrm{DOX} \cdot \mathrm{HCl}$ equivalent per kg body weight. The arrows in the heart, liver, and kidney sections indicate a certain myocardial damage and fracture, the blood oozing and nucleus shrinking of liver tissue, and nephrotoxicity judged from the glomerular mesangial cell proliferation, respectively. The virtual coil indicates the tumor metastasis in thymus. Magnification: 200X.

Abbreviations: DOX, doxorubicin; DOX.HCl, doxorubicin hydrochloride; NG/DOX, DOX-loaded nanogel; NS, normal saline.
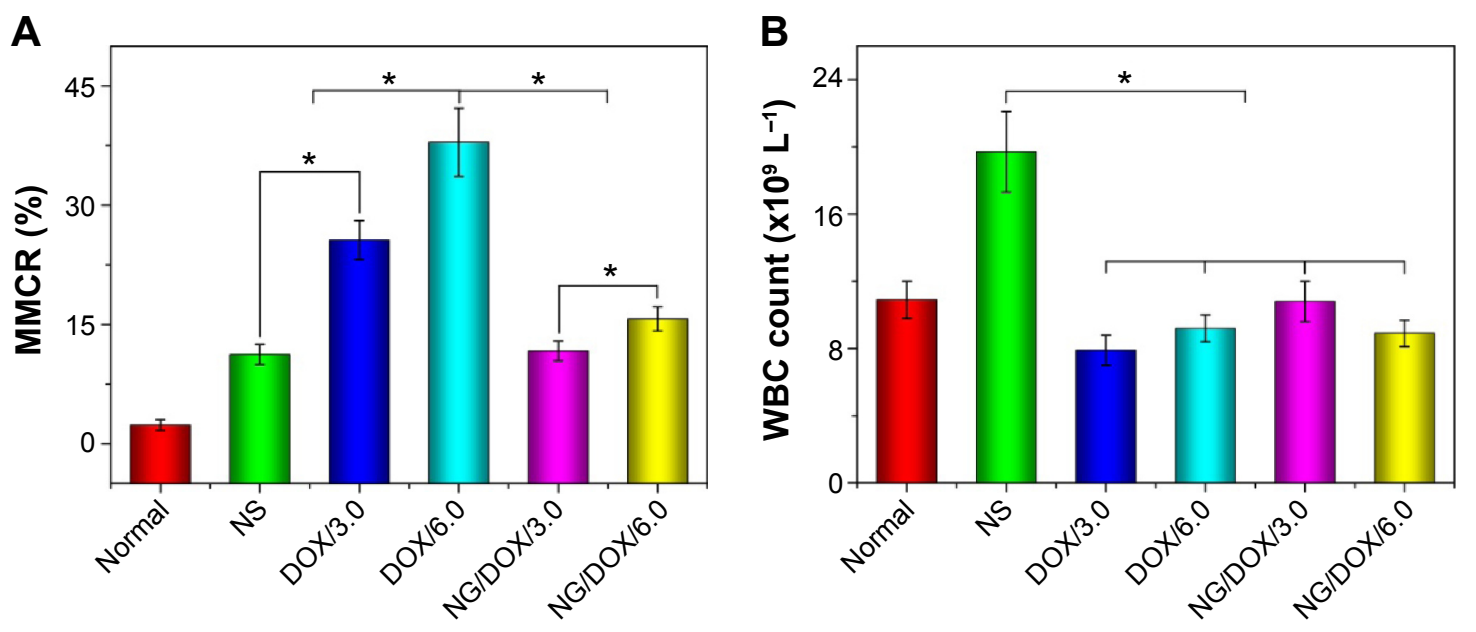

Figure 10 MMCR and $W B C$ count.

Notes: MMCR (A) and WBC count (B) of normal mice, or H22 hepatoma-xenografted BALB/c mice after treatment with NS as control, or free DOX.HCl or NG/DOX at a dosage of $3.0 \mathrm{mg}$ or $6.0 \mathrm{mg} \mathrm{DOX} \cdot \mathrm{HCl}$ equivalent per $\mathrm{kg}$ body weight. Each set of data is represented as mean $\pm S D(n=I 0, * P<0.00 \mathrm{I})$.

Abbreviations: DOX, doxorubicin; DOX.HCl, doxorubicin hydrochloride; NG/DOX, DOX-loaded nanogel; MMCR, marrow micronucleus cell rate; NS, normal saline; WBC, white blood cell; SD, standard deviation. 

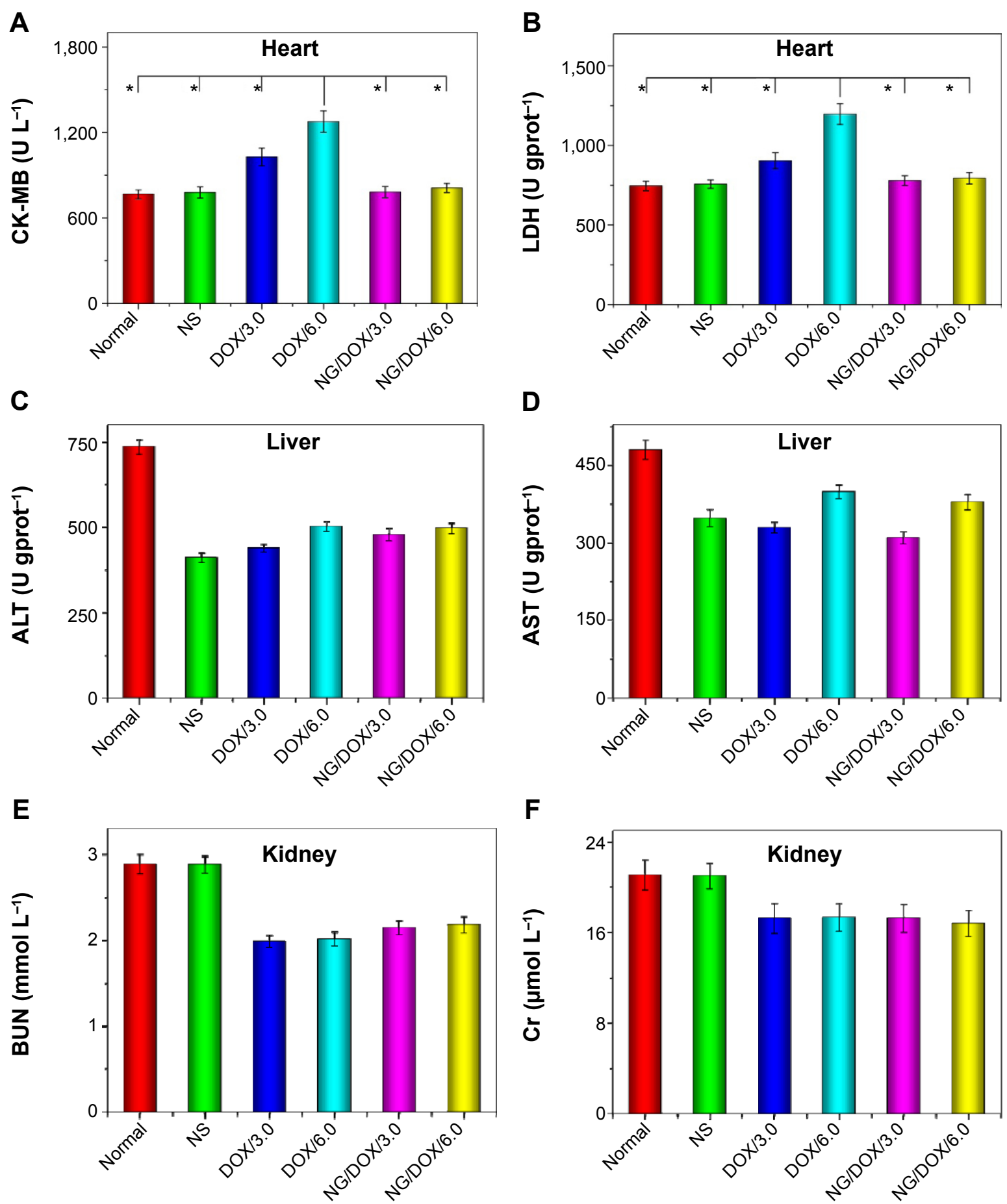

Figure II Biochemical analyses of corresponding organs.

Notes: Evaluations of CK-MB (A, heart), LDH (B, heart), ALT (C, liver), AST (D, liver), BUN (E, kidney), and Cr ( $\mathbf{F}$, kidney) in corresponding internal organs of normal mice or $\mathrm{H} 22$ hepatoma-xenografted BALB/c mice after treatment with NS as control, or free DOX.HCl or NG/DOX at a dosage of $3.0 \mathrm{mg}$ or $6.0 \mathrm{mg} \mathrm{DOX} \cdot \mathrm{HCl}$ equivalent per kg body weight. Each set of data is represented as mean $\pm S D(n=\mid 0, * P<0.001)$.

Abbreviations: DOX, doxorubicin; DOX.HCl, doxorubicin hydrochloride; NG/DOX, DOX-loaded nanogel; NS, normal saline; CK-MB, creatine kinase isoenzyme; LDH, lactate dehydrogenase; ALT, alanine aminotransferase; AST, aspartate aminotransferase; BUN, blood urea nitrogen; $\mathrm{Cr}$, creatinine; SD, standard deviation.

were equivalent to or even lower than those of normal mice. The results illustrated that both free DOX $\cdot \mathrm{HCl}$ and $\mathrm{NG} / \mathrm{DOX}$ did not cause serious impairments of all other organs except heart. The data were consistent with the histopathological results and demonstrated the enhanced security of NG/DOX.

\section{Conclusion}

The reduction-responsive NG/DOX with moderate drug loading content $(10.2 \mathrm{wt} \%)$ and diameter $(\sim 110 \mathrm{~nm})$ was prepared to treat hepatoma in rodent model. As soon as the loading nanogel accumulated in tumor tissue and entered 
A

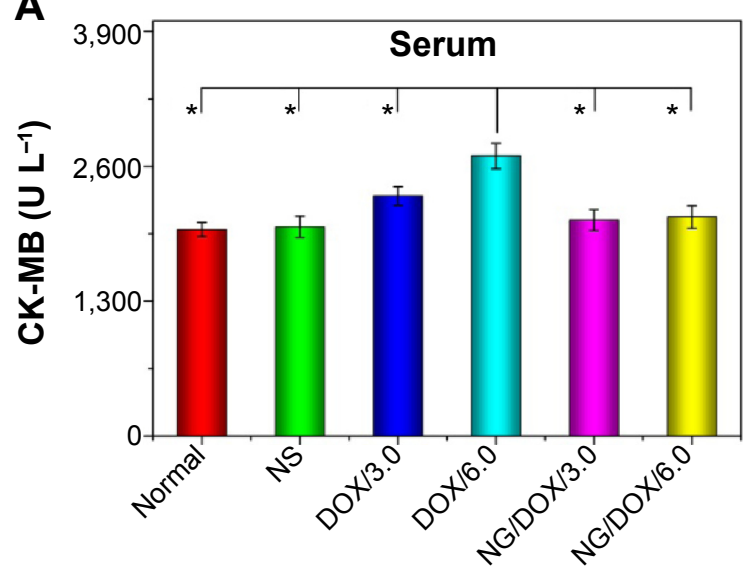

C

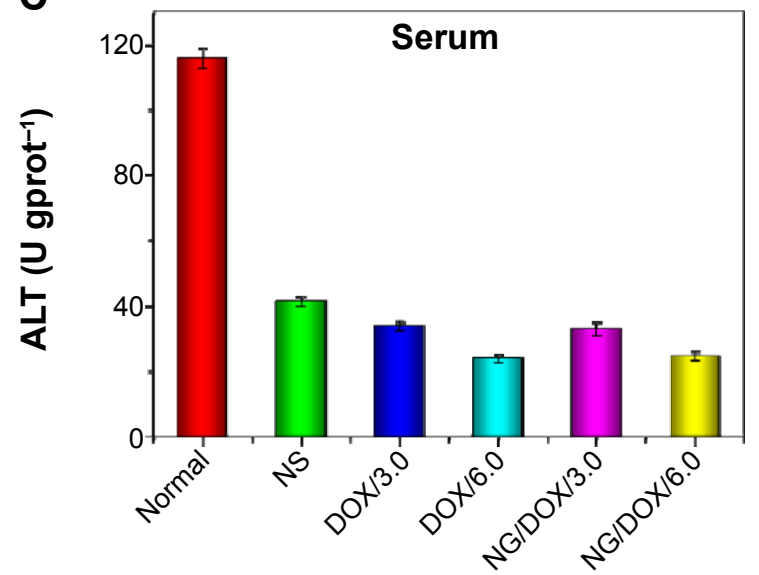

E

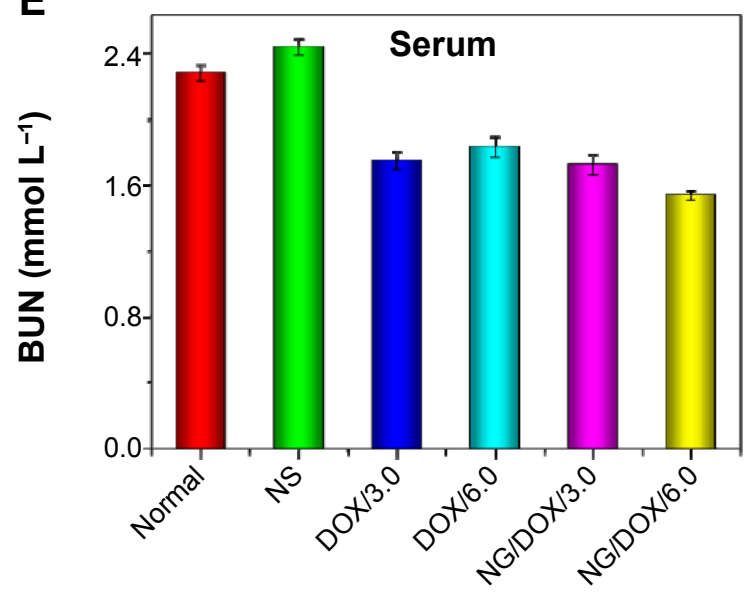

B

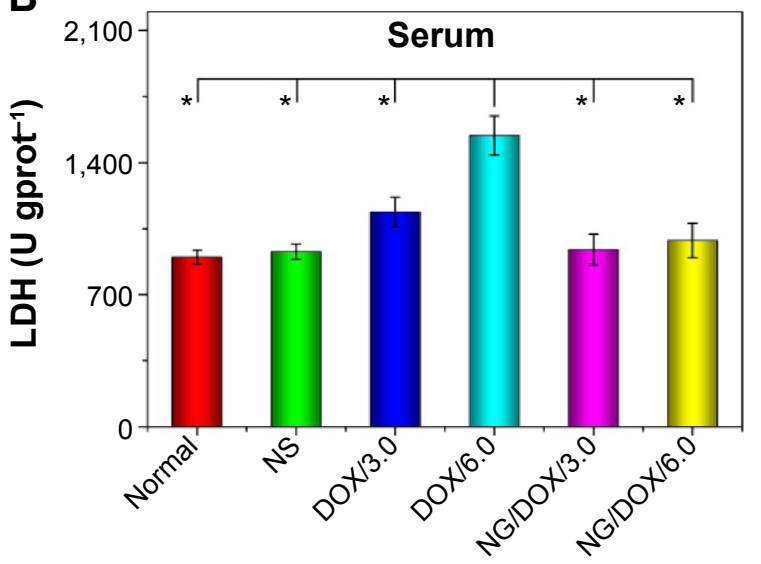

D

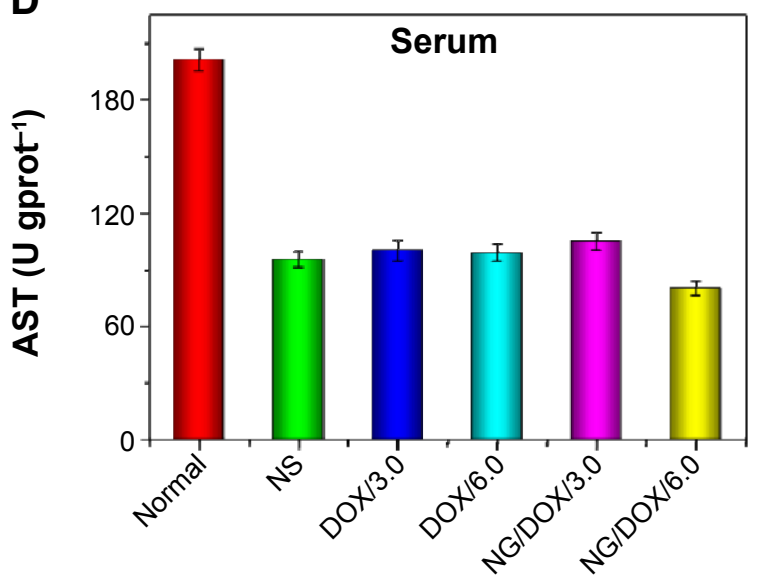

F

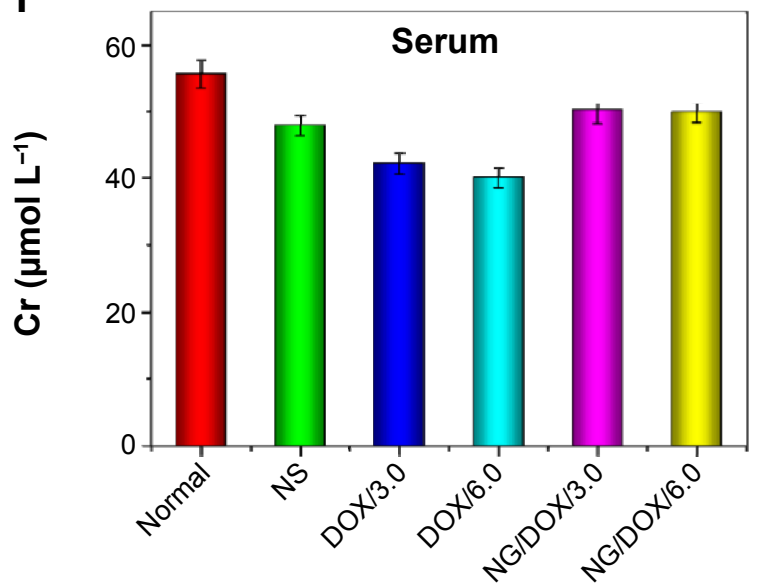

Figure 12 Blood biochemical analyses.

Notes: Evaluations of CK-MB (A), LDH (B), ALT (C), AST (D), BUN (E), and Cr (F) in serum of normal mice or H22 hepatoma-xenografted BALB/c mice after treatment with NS as control, or free DOX.HCl or NG/DOX at a dosage of $3.0 \mathrm{mg}$ or $6.0 \mathrm{mg}$ DOX.HCl equivalent per kg body weight. Each set of data is represented as mean \pm SD $(n=10, * p<0.001)$.

Abbreviations: DOX, doxorubicin; DOX.HCl, doxorubicin hydrochloride; NG/DOX, DOX-loaded nanogel; NS, normal saline; CK-MB, creatine kinase isoenzyme; LDH, lactate dehydrogenase; ALT, alanine aminotransferase; AST, aspartate aminotransferase; BUN, blood urea nitrogen; Cr, creatinine; SD, standard deviation.

into cells, the payload quickly released; this was mediated by the high concentration of intracellular GSH $(\sim 10.0 \mathrm{mM})$, which contributed to the improved efficacy in vivo. Simultaneously, the systemic toxicity of drug was reduced by the stable encapsulation of nanogel and less drug leakage in the process of circulation after IV injection. As we know, DOX is just a model agent, and the targeting intracellular release of other hydrophobic antitumor drugs, like paclitaxel, docetaxel, MTX, and camptothecin, can also be achieved with the reduction-responsive nanogel as a smart nanovehicle. 
Therefore, the intracellular GSH-degradable nanogel exhibits a great prospect for advanced chemotherapy of malignancy with enhanced efficacy and security.

\section{Acknowledgments}

This research was financially supported by the National Natural Science Foundation of China (numbers 51303174, 51233004, 51390484, 51321062, 51473165, 51203153, 51273196, and 21104076), the Scientific Development Program of Jilin Province (numbers 20140520050JH, 20140309005GX, and 20130206058GX), and the Frontier Discipline Innovation Project of Bethune Medical Department (number 2013101006).

\section{Disclosure}

The authors report no conflicts of interest in this work.

\section{References}

1. Quail DF, Joyce JA. Microenvironmental regulation of tumor progression and metastasis. Nat Med. 2013;19(11):1423-1437.

2. Joyce JA, Fearon DT. T cell exclusion, immune privilege, and the tumor microenvironment. Science. 2015;348(6230):74-80.

3. Xu W, Ding J, Li L, Xiao C, Zhuang X, Chen X. Acid-labile boronatebridged dextran-bortezomib conjugate with up-regulated hypoxic tumor suppression. Chem Commun. 2015;51(31):6812-6815.

4. Shi F, Ding J, Xiao C, et al. Intracellular microenvironment responsive PEGylated polypeptide nanogels with ionizable cores for efficient doxorubicin loading and triggered release. J Mater Chem. 2012;22(28): 14168-14179.

5. Ding J, Xu W, Zhang Y, et al. Self-reinforced endocytoses of smart polypeptide nanogels for "on-demand" drug delivery.J Control Release. 2013;172(2):444-455.

6. Ding J, Shi F, Xiao C, et al. One-step preparation of reduction-responsive poly(ethylene glycol)-poly(amino acid)s nanogels as efficient intracellular drug delivery platforms. Polym Chem. 2011;2(12):2857-2864.

7. Montero D, Tachibana C, Rahr Winther J, Appenzeller-Herzog C. Intracellular glutathione pools are heterogeneously concentrated. Redox Biol. 2013;1(1):508-513.

8. Ding J, Chen J, Li D, et al. Biocompatible reduction-responsive polypeptide micelles as nanocarriers for enhanced chemotherapy efficacy in vitro. J Mater Chem B. 2013;1(1):69-81.

9. Yao C, Tai Z, Wang X, et al. Reduction-responsive cross-linked stearyl peptide for effective delivery of plasmid DNA. Int J Nanomedicine. 2015;10:3403-3416.

10. Kanapathipillai M, Brock A, Ingber DE. Nanoparticle targeting of anti-cancer drugs that alter intracellular signaling or influence the tumor microenvironment. Adv Drug Deliv Rev. 2014;79-80:107-118.

11. Khorsand B, Lapointe G, Brett C, Oh JK. Intracellular drug delivery nanocarriers of glutathione-responsive degradable block copolymers having pendant disulfide linkages. Biomacromolecules. 2013;14(6):2103-2111.

12. Ding J, Shi F, Xiao C, Zhuang X, He C, Chen X. Facile preparation of $\mathrm{pH}$ and reduction responsive PEGylated polypeptide nanogel for efficient doxorubicin loading and intracellular delivery. $J$ Control Release. 2013;172(1):E40-E41.

13. O'Reilly RK, Hawker CJ, Wooley KL. Cross-linked block copolymer micelles: functional nanostructures of great potential and versatility. Chem Soc Rev. 2006;35(11):1068-1083.

14. Huo M, Yuan J, Tao L, Wei Y. Redox-responsive polymers for drug delivery: from molecular design to applications. Polym Chem. 2014;5(5):1519-1528.
15. Li Y, Lokitz BS, Armes SP, McCormick CL. Synthesis of reversible shell cross-linked micelles for controlled release of bioactive agents. Macromolecules. 2006;39(8):2726-2728.

16. Koo AN, Lee HJ, Kim SE, et al. Disulfide-cross-linked PEG-poly(amino acid)s copolymer micelles for glutathione-mediated intracellular drug delivery. Chem Commun. 2008;(48):6570-6572.

17. Wei R, Cheng L, Zheng M, et al. Reduction-responsive disassemblable core-cross-linked micelles based on poly(ethylene glycol)- $b$ poly( $N$-2-hydroxypropyl methacrylamide)-lipoic acid conjugates for triggered intracellular anticancer drug release. Biomacromolecules. 2012;13(8):2429-2438.

18. Li Y, Xiao K, Luo J, et al. Well-defined, reversible disulfide crosslinked micelles for on-demand paclitaxel delivery. Biomaterials. 2011;32(27):6633-6645.

19. Cheng Y, He C, Xiao C, et al. Reduction-responsive cross-linked micelles based on PEGylated polypeptides prepared via click chemistry. Polym Chem. 2013;4(13):3851-3858.

20. Xing T, Lai B, Ye X, Yan L. Disulfide core cross-linked PEGylated polypeptide nanogel prepared by a one-step ring opening copolymerization of $\mathrm{N}$-carboxyanhydrides for drug delivery. Macromol Biosci. 2011;11(7):962-969.

21. Ding J, Shi F, Li D, Chen L, Zhuang X, Chen X. Enhanced endocytosis of acid-sensitive doxorubicin derivatives with intelligent nanogel for improved security and efficacy. Biomater Sci. 2013;1(6):633-646.

22. Xu W, Ding J, Xiao C, Li L, Zhuang X, Chen X. Versatile preparation of intracellular-acidity-sensitive oxime-linked polysaccharidedoxorubicin conjugate for malignancy therapeutic. Biomaterials. 2015;54(0):72-86.

23. Banzato A, Bobisse S, Rondina M, et al. A paclitaxel-hyaluronan bioconjugate targeting ovarian cancer affords a potent in vivo therapeutic activity. Clin Cancer Res. 2008;14(11):3598-3606.

24. Ernsting MJ, Murakami M, Roy A, Li S-D. Factors controlling the pharmacokinetics, biodistribution and intratumoral penetration of nanoparticles. J Control Release. 2013;172(3):782-794.

25. Wang J, Xu W, Ding J, et al. Cholesterol-enhanced polylactide-based stereocomplex micelle for effective delivery of doxorubicin. Materials. 2015;8(1):216-230

26. Lee CC, Gillies ER, Fox ME, et al. A single dose of doxorubicinfunctionalized bow-tie dendrimer cures mice bearing C-26 colon carcinomas. Proc Natl Acad Sci U S A. 2006;103(45):16649-16654.

27. Lammers T, Subr V, Ulbrich K, et al. Simultaneous delivery of doxorubicin and gemcitabine to tumors in vivo using prototypic polymeric drug carriers. Biomaterials. 2009;30(20):3466-3475.

28. Miranda CJ, Makui H, Soares RJ, et al. Hfe deficiency increases susceptibility to cardiotoxicity and exacerbates changes in iron metabolism induced by doxorubicin. Blood. 2003;102(7):2574-2580.

29. Magge RS, DeAngelis LM. The double-edged sword: neurotoxicity of chemotherapy. Blood Rev. 2015;29(2):93-100.

30. DEMPKE WCM. Targeted therapy for NSCLC-A double-edged sword? Anticancer Res. 2015;35(5):2503-2512.

31. Decaudin D. Primary human tumor xenografted models ('tumorgrafts') for good management of patients with cancer. Anticancer Drugs. 2011; 22(9):827-841.

32. Ding J, Xiao C, Li Y, et al. Efficacious hepatoma-targeted nanomedicine self-assembled from galactopeptide and doxorubicin driven by twostage physical interactions. J Control Release. 2013;169(3):193-203.

33. Bae Y, Nishiyama N, Fukushima S, Koyama H, Yasuhiro M, Kataoka K. Preparation and biological characterization of polymeric micelle drug carriers with intracellular $\mathrm{pH}$-triggered drug release property: tumor permeability, controlled subcellular drug distribution, and enhanced in vivo antitumor efficacy. Bioconjugate Chem. 2005;16(1):122-130.

34. Peer D, Karp JM, Hong S, Farokhzad OC, Margalit R, Langer R. Nanocarriers as an emerging platform for cancer therapy. Nat Nanotechnol. 2007;2(12):751-760.

35. Taniguchi Y, Kawano K, Minowa T, Sugino T, Shimojo Y, Maitani Y. Enhanced antitumor efficacy of folate-linked liposomal doxorubicin with TGF- $\beta$ type I receptor inhibitor. Cancer Sci. 2010; 101(10):2207-2213 
36. Sun D, Ding J, Xiao C, Chen J, Zhuang X, Chen X. pH-responsive reversible PEGylation improves performance of antineoplastic agent. Adv Healthc Mater. 2015;4(6):844-855.

37. Aravind L, Dixit VM, Koonin EV. Apoptotic molecular machinery: vastly increased complexity in vertebrates revealed by genome comparisons. Science. 2001;291(5507):1279-1284.

38. Porter AG, Jänicke RU. Emerging roles of caspase-3 in apoptosis. Cell Death Differ. 1999;6(2):99-104.

39. Lu CD, Altieri DC, Tanigawa N. Expression of a novel antiapoptosis gene, survivin, correlated with tumor cell apoptosis and p53 accumulation in gastric carcinomas. Cancer Res. 1998;58(9):1808-1812.

40. Ghosh SK, Yigit MV, Uchida M, et al. Sequence-dependent combination therapy with doxorubicin and a surviving-specific small interfering RNA nanodrug demonstrates efficacy in models of adenocarcinoma. Int J Cancer. 2014;134(7):1758-1766.

41. Kawasaki H, Altieri DC, Lu CD, Toyoda M, Tenjo T, Tanigawa N. Inhibition of apoptosis by survivin predicts shorter survival rates in colorectal cancer. Cancer Res. 1998;58(22):5071-5074.

42. Fairbrother WJ, Ashkenazi A. Designer proteins to trigger cell death. Cell. 2014;157(7):1506-1508.

43. Storm G, van Hoesel QGCM, de Groot G, Kop W, Steerenberg PA, Hillen FC. A comparative study on the antitumor effect, cardiotoxicity and nephrotoxicity of doxorubicin given as a bolus, continuous infusion or entrapped in liposomes in the Lou/M Wsl rat. Cancer Chemother Pharmacol. 1989;24(6):341-348.
44. Laurell G, Bagger-Sjöbäck D. Degeneration of the organ of Corti following intravenous administration of cisplatin. Acta Otolaryngol. 1991;111(3):891-898.

45. Bucak A, Ozdemir C, Ulu S, et al. Investigation of protective role of curcumin against paclitaxel-induced inner ear damage in rats. Laryngoscope. 2015;125(5):1175-1182.

46. Chen H, Rupa DS, Tomar R, Eastmond DA. Chromosomal loss and breakage in mouse bone marrow and spleen cells exposed to benzene in vivo. Cancer Res. 1994;54(13):3533-3539.

47. Homma Y, Taniguchi K, Nakazawa M, et al. Changes in the immune cell population and cell proliferation in peripheral blood after gemcitabine-based chemotherapy for pancreatic cancer. Clin Transl Oncol. 2014;16(3):330-335.

48. Das M, Jain R, Agrawal AK, Thanki K, Jain S. Macromolecular bipill of gemcitabine and methotrexate facilitates tumor-specific dual drug therapy with higher benefit-to-risk ratio. Bioconjugate Chem. 2014; 25(3):501-509.
International Journal of Nanomedicine

\section{Publish your work in this journal}

The International Journal of Nanomedicine is an international, peerreviewed journal focusing on the application of nanotechnology in diagnostics, therapeutics, and drug delivery systems throughout the biomedical field. This journal is indexed on PubMed Central, MedLine, CAS, SciSearch ${ }^{\circledR}$, Current Contents ${ }^{\circledR} /$ Clinical Medicine,

\section{Dovepress}

Journal Citation Reports/Science Edition, EMBase, Scopus and the Elsevier Bibliographic databases. The manuscript management system is completely online and includes a very quick and fair peer-review system, which is all easy to use. Visit http://www.dovepress.com/ testimonials.php to read real quotes from published authors. 